\title{
Analysis of porcine body size variation using re-sequencing data of miniature and large pigs
}

\author{
C. Reimer ${ }^{1,9^{*}} \mathbb{D}$, C.-J. Rubin ${ }^{2}$, A. R. Sharifi ${ }^{1,9}$, N.-T. Ha ${ }^{1,9}$, S. Weigend ${ }^{3,9}$, K.-H. Waldmann ${ }^{4}$, O. Distl ${ }^{5}$, S. D. Pant ${ }^{6}$, \\ M. Fredholm ${ }^{7}$, M. Schlather ${ }^{8,9}$ and H. Simianer ${ }^{1,9}$
}

\begin{abstract}
Background: Domestication has led to substantial phenotypic and genetic variation in domestic animals. In pigs, the size of so called minipigs differs by one order of magnitude compared to breeds of large body size. We used biallelic SNPs identified from re-sequencing data to compare various publicly available wild and domestic populations against two minipig breeds to gain better understanding of the genetic background of the extensive body size variation. We combined two complementary measures, expected heterozygosity and the composite likelihood ratio test implemented in "SweepFinder", to identify signatures of selection in Minipigs. We intersected these sweep regions with a measure of differentiation, namely $F_{S T}$, to remove regions of low variation across pigs. An extraordinary large sweep between 52 and $61 \mathrm{Mb}$ on chromosome $X$ was separately analyzed based on SNP-array data of $F_{2}$ individuals from a cross of Goettingen Minipigs and large pigs.
\end{abstract}

Results: Selective sweep analysis identified putative sweep regions for growth and subsequent gene annotation provided a comprehensive set of putative candidate genes. A long swept haplotype on chromosome $X$, descending from the Goettingen Minipig founders was associated with a reduction of adult body length by $3 \%$ in $F_{2}$ cross-breds.

Conclusion: The resulting set of genes in putative sweep regions implies that the genetic background of body size variation in pigs is polygenic rather than mono- or oligogenic. Identified genes suggest alterations in metabolic functions and a possible insulin resistance to contribute to miniaturization. A size QTL located within the sweep on chromosome $X$, with an estimated effect of $3 \%$ on body length, is comparable to the largest known in pigs or other species. The androgen receptor $A R$, previously known to influence pig performance and carcass traits, is the most obvious potential candidate gene within this region.

Keywords: Goettingen Minipig, Whole genome resequencing, Body size, X-chromosomal QTL

\section{Background}

The livestock species of today display vast phenotypic variation. Domestication and breed formation processes have shaped these species by increasing the variation in traits related to, performance, fitness, morphology and appearance, thereby changing the - phenotypically rather uniform - wild ancestors to the illustrious collection of our modern breeds. Focusing on body size, Haldane [1]

\footnotetext{
* Correspondence: creimer@gwdg.de

${ }^{1}$ Animal Breeding and Genetics Group, Department of Animal Sciences,

University of Goettingen, Albrecht-Thaer-Weg 3, 37075 Goettingen, Germany

${ }^{9}$ Center for Integrated Breeding Research, University of Goettingen,

Albrecht-Thaer-Weg 3, 37075 Goettingen, Germany

Full list of author information is available at the end of the article
}

discussed a general principle as to why the horse is larger than the rabbit, or the cow is larger than the pig, and suggested that there must be a right size for a certain form of a body and a change in size must be accompanied with a change in form. In contradiction to that, a wide range of body size or weight is often seen within a single species, as for example in dogs [2]. Taking the example of pigs (Sus scrofa), the process of domestication of the wild boar led to animals that span from large fattening pigs to the so called 'miniature pigs' or simplified 'minipigs'. Their sizes differ by up to one order of magnitude. Among the minipigs the Goettingen Minipig (GMP) is one of the smallest breeds under a stringent breeding scheme [3, 4]. The

(c) The Author(s). 2018 Open Access This article is distributed under the terms of the Creative Commons Attribution 4.0 International License (http://creativecommons.org/licenses/by/4.0/), which permits unrestricted use, distribution, and reproduction in any medium, provided you give appropriate credit to the original author(s) and the source, provide a link to the Creative Commons license, and indicate if changes were made. The Creative Commons Public Domain Dedication waiver (http://creativecommons.org/publicdomain/zero/1.0/) applies to the data made available in this article, unless otherwise stated. 
Goettingen Minipig is a composite breed developed in the 1960's at the former Institute of Animal Breeding and Genetics at the Georg-August-University Göttingen in Germany. It was founded by crossing Minnesota Minipigs (MMP) with Vietnamese Potbellied Pigs (VPP). Later German Landrace pigs (LAR) were introduced to produce uniformly white animals [5]. This pig breed shows a form of miniaturization called "proportional dwarfism" which Simianer and Köhn [3] suggested to be a form of pituitary dwarfism, caused by lower secretion of growth hormones from the pituitary gland, leading to a decreased secretion of the insulin-like growth factor 1 (IGF1).

The availability of porcine SNP chips offers the possibility to screen the genome for regions carrying genetic variants associated with the reduced size of minipigs. Gaerke et al. [6] conducted a study on signatures of selection in GMP, MMP, VPP and LAR, using a $60 \mathrm{k}$ SNP chip. They found that alleles from all founder breeds were still segregating in the GMP and identified numerous putatively positively selected regions in the GMP. They suggested that a pathway connecting SOCS2 and GRB10 with IGF1 could exist that plays an important role in the dwarfism of the GMP. Due to the limited marker density of the SNP array it was not possible to reveal causal mutations.

The current reference genome is based on the sequence of a Duroc pig with the first studies, using this reference to provide insight into the porcine demography and evolution [7] and into the patterns that domestication and anthropogenic selection have left in the porcine genome [8], which were published in 2012. While these studies used diverse sets of pig breeds from all over the world, minipigs were not included. The very same month, the genome of a highly inbred Chinese Wuzhishan minipig was published [9] as an additional reference genome for Asian pigs, which have been domesticated independently from European pigs [10]. The present study aims at comparing WGS data of a diverse set of pig breeds to unveil the genetic mechanisms behind body size variation, and more specifically the miniaturization in pigs. In working towards this aim, we compared a group of miniature pig breeds to a group of large pig breeds by screening for highly differentiated regions under selection in the minipigs. Such candidate regions were subsequently screened for candidate genes with a putative effect on growth or body size, and the postulated effects on body-size of one of the identified candidate region was confirmed with data of an independent crossbreeding experiment.

\section{Results}

\section{Number of SNPs}

Biallelic SNPs are the most common class of variants used in genetic studies of animal genomes. Since SNP calling from WGS data is not limited to prior knowledge on variant positions, the number of SNPs is an indicator of variability in the analysed dataset and of strictness of the variant discovery and filtering. SNP calling from the DNA sequencing data revealed $46 \times 10^{6}$ biallelic SNPs genome-wide, of which $29 \times 10^{6}$ were polymorphic or fixed for the alternative allele in the minipigs. After filtering, $35 \times 10^{6}$ loci were polymorphic in all samples and $19.8 \times 10^{6}$ only in minipigs. For European domestics, European wild boars, Asian domestics and Asian wild boars, these numbers were $19 \times 10^{6}, 9.4 \times 10^{6}, 19.5 \times 10^{6}$ and $19.2 \times 10^{6}$, respectively. Subsequent in-silico pooling left $27.6 \times 10^{6}$ loci with sufficient information to compare minipigs against large pigs.

\section{Phylogeny}

When comparing large pig breeds to minipigs, it is important to account for stratification within each contrasting group to ensure, that no breed specific signals will be identified. The analysis of genetic distances between sampled breeds revealed a clear division of European and Asian large pigs, with minipigs clustering closer to the Asian pigs (Fig. 1; see also MDS in Additional file 1). Estimation of $F_{S T}$ also showed that the minipigs were closer to the Asian breeds than to the European breeds $\left(F_{S T}=0.08\right.$ and 0.12 , respectively), while both minipig breeds were marginally closer to the domestic groups of both continents than to the respective wild boars. This effect is smaller for the GMP (GMP to European domestic/ wild: 0.14, 0.16; GMP to Asian domestic/ wild: $0.10,0.11$ ), whereas there is clear distinction for the BMP, which is much closer to both domestic groups than to the wild boars (BMP to European domestic/ wild: 0.07, 0.14; BMP to Asian domestic/ wild: 0.08, 0.11). The $F_{S T}$ value between both minipig groups is 0.09 . The highest overall differentiation has been estimated between European and Asian wild boars (additional information in Additional file 2 and Additional file 3).

\section{Selective sweeps}

We searched for genomic regions under selective pressure for body size using a so-called selective sweep analysis, employing a combination of decreased expected heterozygosity, SweepFinder and $\mathrm{F}_{\mathrm{ST}}$, and subsequently identified candidate genes within these regions. The selective sweep analysis revealed considerable parts of the genome as putatively being targeted by selection for growth. Not every chromosome was affected equally. Most of the 49 identified signals extended between $1 \mathrm{Mb}$ and $2.5 \mathrm{Mb}$, but one on chromosome 14 reached nearly $10 \mathrm{Mb}$. The other large signals were located on chromosomes $5(2.8$ and $4.3 \mathrm{Mb})$, 8 (4.6 Mb), 13 (5.2 and 2.9 Mb), 14 (3.6 Mb) (Fig. 2) and chromosome X (48 Mb; not shown). SweepFinder detected fewer, but larger regions, whereas the regions detected by decreased heterozygosity were more numerous but smaller. The exceptionally large region on chromosome 14 consists 


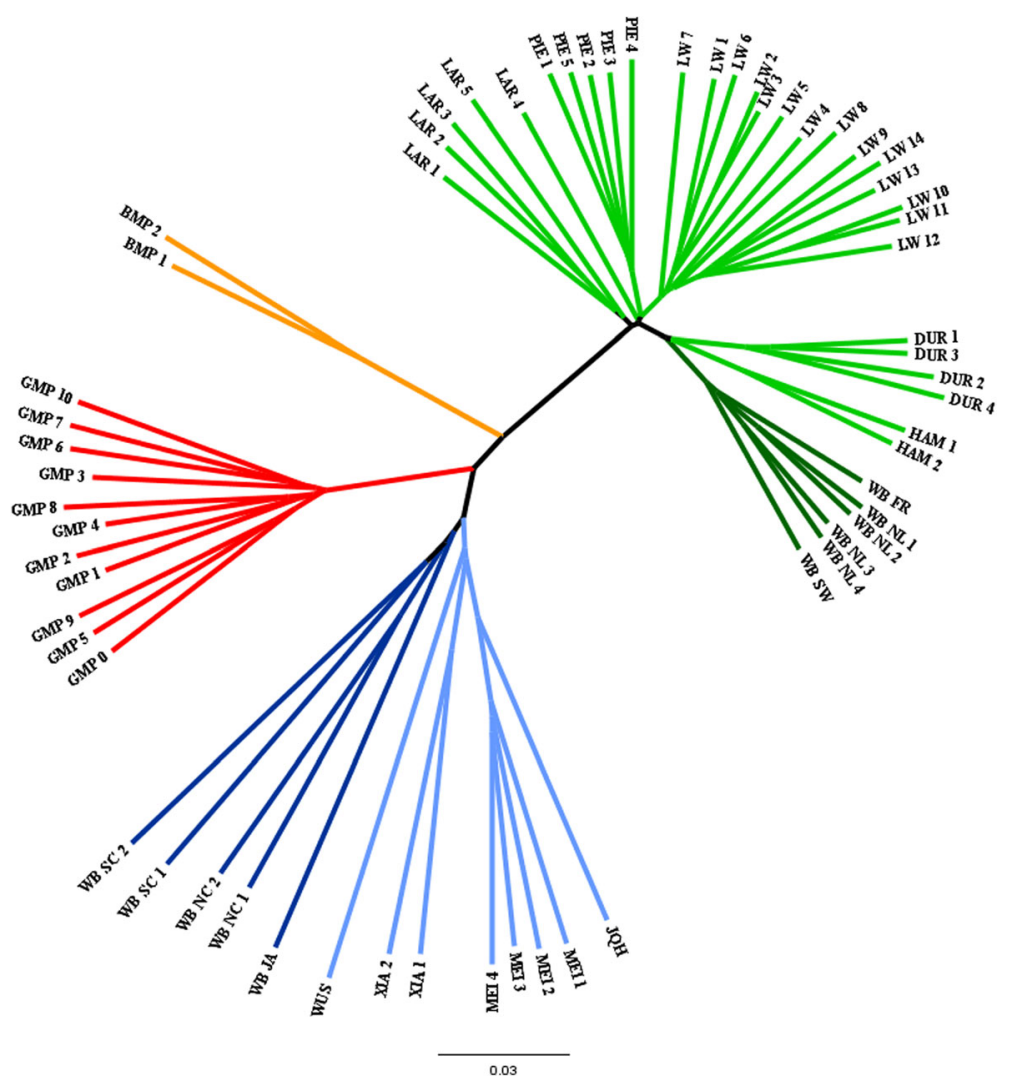

Fig. 1 Neighbor-joining tree computed from pairwise IBS distances. Based on SNP data of the randomly selected chromosomes 1,8 and 13 for all individuals (due to computational limitations). Asian wild boars in dark blue, Asian domestics in light blue, European wild boars in dark green, European domestics in light green, Mini-LEWE in orange and Goettingen Minipigs in red

of an accumulation of many small signals reflecting reduced heterozygosity and two large signals from SweepFinder. The union of both signals gives a nearly uninterrupted huge selective sweep signal.

\section{Genes in sweeps and gene ontology over-representation} All genes within sweep regions were annotated and gene ontologies (GO's), which represent functional categories, linked to every detected gene were checked for over-representation of certain GOs within sweeps compared to the unselected background, to identify functional categories rather than single candidates. The Ensembl porcine gene set 79 annotation within sweep regions on the autosomes revealed 524 genes (Additional file 4), belonging to 2006 unique gene-ontology terms. 55 of these gene ontologies were found to be overrepresented within sweeps by using a Fisher's exact test $p$-value lower than the $5 \%$ quantile threshold of the empirical distribution function for the respective ontology. Table 1 shows a selection of gene ontologies over-represented in putative sweeps (see also Additional file 5).

A literature review for all genes belonging to the overrepresented GO terms with a focus on properties characterizing minipigs revealed a comprehensive set of genes with interesting putative functions (Table 2). Among them are genes like COMT and PATZ1 with direct effects on growth or size in other organisms, ACOT4 and PKP2, which are involved in growth factor signaling, or genes directly linked to growth in swine, for example PPARG that is suspected to be a key factor in porcine growth, conformation and fatness. Additionally, we found a considerable number of genes with links to the MAPK signaling cascade, e.g. MAPK1 and PTPRR, involved in glucose and lipid metabolism, or putatively responsible for insulin resistance or diabetes type II or obesity.

\section{Strong selective sweep on chromosome $\mathrm{X}$}

The major selective sweep on chromosome $\mathrm{X}$ (chr. X) known from the studies of Rubin et al. [8] and Ai et al. [11] is also found in the minipigs. It is known that this sweep consists of two majorly un-recombining haplotypes of about 9 and $39 \mathrm{Mb}$, respectively. Figure 3a shows a substantial decrease of the expected heterozygosity within the minipigs in a $48 \mathrm{Mb}$ region in the middle of chromosome $\mathrm{X}$ between $52 \mathrm{Mb}$ and $100 \mathrm{Mb}$. The fixation index shows that this region consists of two separate sub-regions. The 

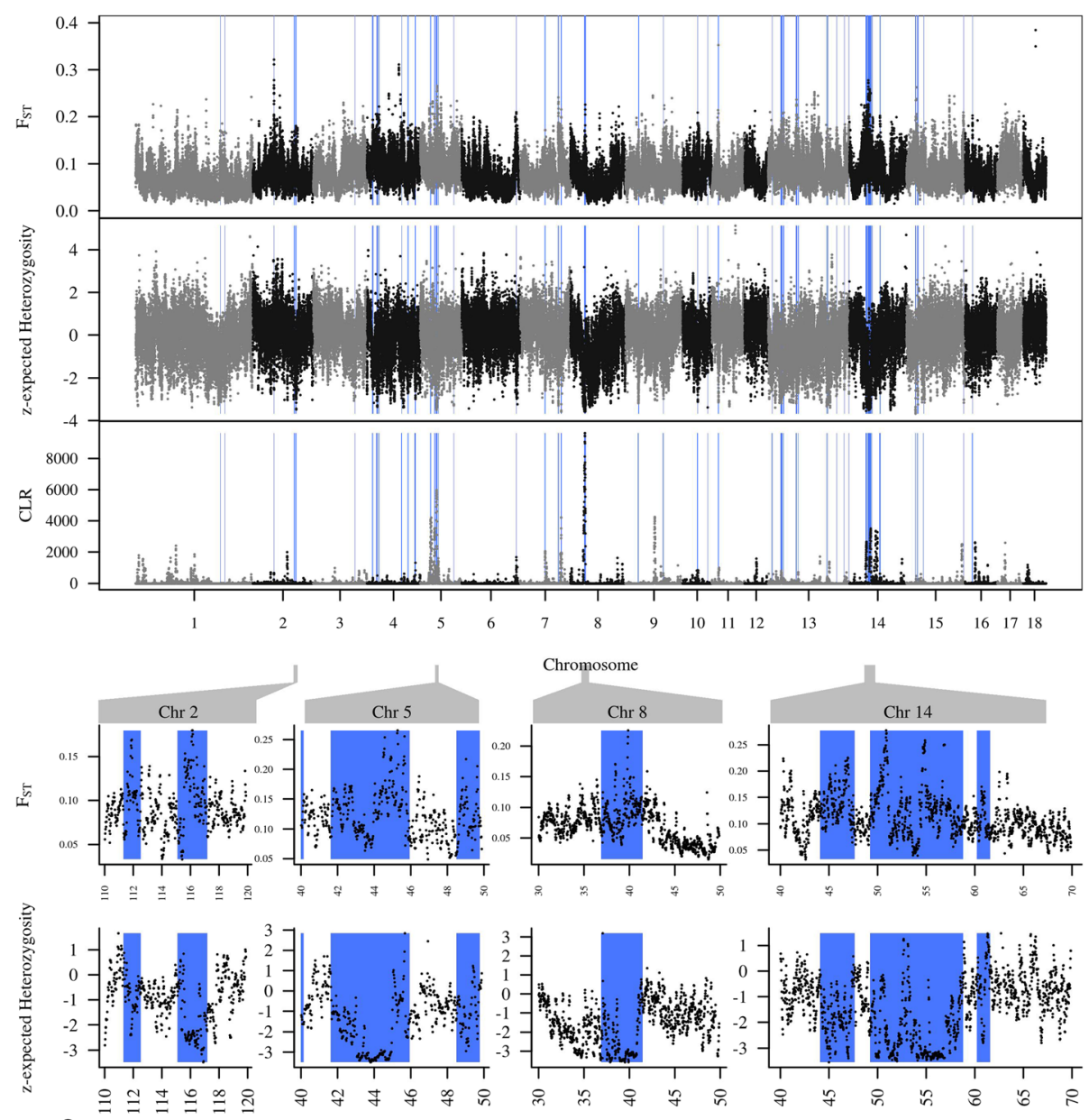

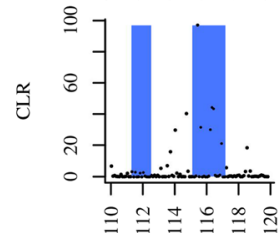

Pos

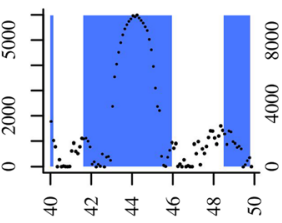

Pos

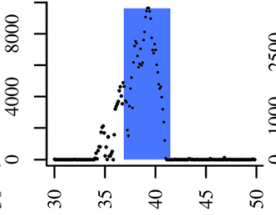

Pos

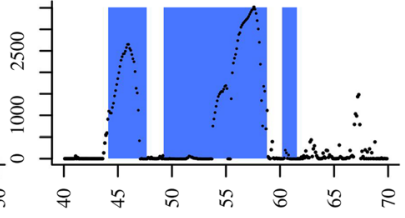

Pos

Fig. 2 CLR test and normalized expected heterozygosity within minipigs and $\mathrm{F}_{\mathrm{ST}}$ between large pigs and minipigs. Regions on chromosomes 2, 5, 8 and 14 identified as putative selective sweeps are highlighted; Blue rectangles underlie detected putative sweeps

first part, approximately inside the interval $52 \mathrm{Mb}$ to $61 \mathrm{Mb}$, is typical for the minipigs and shared with South Asian pigs, whereas differentiation in the second part implies that the minipigs are also similar to some breeds from North Asia. We postulated that this genomic region might have an effect on body size and therefore utilized data of a former cross-breeding experiment, to estimate QTL effects for each existent haplotype.

The phylogenetic tree of all sequenced animals based on all markers inside the first region (Fig. 4), shows that the haplotype carried by the minipigs is shared with the Xiang pigs and two wild boars from South China. The sub-tree for the second region clusters the samples into two main groups, the first comprising the minipigs, the
Xiang, the Meishan, the Jiangquhai and the South Chinese wild boars, and the second all European breeds and the wild boars from North China and Japan (Additional file 6).

\section{Analysis of SNP chip data}

Since the haplotype carried in the region chrX:52-61 Mb appears to be typical for minipigs, we used genotyping data from two former studies $[6,12]$ to determine the haplotypic state of animals with recorded phenotypes in order to enable the estimation of the effect of the minipig haplotype on size. The Illumina PorcineSNP60 BeadChip contains 23 SNPs located on chromosome X between 52 and $61 \mathrm{Mb}$ according to the current map based on the genome build 10.2. Filtering removed 7 
Table 1 Selected gene ontologies over-represented in putative sweeps

\begin{tabular}{llllll}
\hline No. & Fisher-P & Empirical $p$-value & Number of genes in term and sweep & Fold Enr. & GO Term Name \\
\hline 1 & 0.0017 & 0.0002 & 7 & 3.94 & Z disc \\
2 & 0.0012 & 0.0014 & 4 & 0.26 & $\begin{array}{l}\text { negative regulation of transcription from RNA polymerase } \\
\text { Il promoter }\end{array}$ \\
3 & 0.0050 & 0.0040 & 5 & 4.38 & $\begin{array}{l}\text { protein tyrosine/serine/threonine phosphatase activity } \\
4\end{array}$ \\
\hline 0.0172 & 0.0059 & 4 & 3.94 & Microvillus \\
5 & 0.0060 & 0.0063 & 4 & 5.25 & regulation of alternative mRNA splicing, via spliceosome \\
6 & 0.0149 & 0.0067 & 13 & 1.99 & mitochondrial inner membrane \\
7 & 0.0033 & 0.0067 & 10 & 2.75 & protein dephosphorylation \\
8 & 0.0024 & 0.0078 & 54 & 1.52 & Mitochondrion \\
9 & 0.0096 & 0.0081 & 3 & 6.44 & leukocyte tethering or rolling \\
10 & 0.0125 & 0.012 & 3 & 5.91 & ventricular cardiac muscle cell action potential \\
22 & 0.0272 & 0.0222 & 10 & 2.13 & actin cytoskeleton \\
25 & 0.0101 & 0.0239 & 2 & 11.81 & mitochondrial electron transport, ubiquinol to cytochrome c \\
27 & 0.0101 & 0.0248 & 2 & 11.81 & positive regulation of growth \\
31 & 0.006 & 0.0286 & 4 & 5.25 & social behavior \\
\hline
\end{tabular}

individuals for poor genotyping (call rate $<10 \%$ ), 3 SNPs that were missing and 13 SNPs, which had a low minor allele frequency. 8 SNPs (Additional file 7) passed the filtering, three of them in the beginning of the region around $53 \mathrm{Mb}$ (MARC0056564, MARC0046345, H3GA0051807), three in the center around $57 \mathrm{Mb}$ (INRA0056742, H3GA0051810, MARC0013223) and two at the end around $60 \mathrm{Mb}$ (INRA0056744, H3GA0051814). At the first three loci, all minipigs are homozygous for a guanine-cytosin-guanin haplotype, while also two Duroc females from the Danish study are found being heterozygous for this haplotype. Therefore, these three markers are not informative to determine the origin of the respective allele in the cross-breds. The genotypes at the three

Table 2 Candidate genes from potentially enriched ontologies with putative functional link to minipigs

\begin{tabular}{lll}
\hline Gene name & Function & Reference \\
\hline ACACB & Downregulated by TGFB1; influencing type-II-diabetes; & Zhou et al. [87]; Ma et al. [88] \\
obesity and lipid metabolism & Muise et al. [89] \\
ADAMTS12 & Linked to FGF21 in mice & Llamazares et al. [90] \\
COMT & Blocks Ras/ MAPK pathway & Sata et al. [33] \\
DUSP28 & Reduced birth weight in humans & Wang et al. [91] \\
HYAL1, HYAL2 & Activator of MAPK pathway & Vallet et al. [92] \\
LTBP1 & Overexpressed in the placenta of the smallest pig fetuses & Lango Allen et al. [31] \\
MAGOH & TGFB signaling, role in the regulation of human height & Roignant and Treisman [93] \\
MAPK1 & Influences MAPK & Reviewed by Cobb et al. [94] \\
NDUFB9 & Coding central proteins ERK2 in the Ras/ MAPK & Riedl et al. [95] \\
OSM & Severe growth-hormone deficiency & Sanchez-Infantes et al. [96] \\
PATZ1 & Diabetes type II & Valentino et al. [34] \\
PKP2 & Null mice were retarded in growth, Homozygote animals were & Kazlauskas [97] \\
PPARG & 10 to 20\% smaller, than their litter mates of the same sex & Crooks et al. [43]; Hevener et al. [42]; \\
PRKAR2A & Associates EGF & Puig-Oliveras et al. [44]; Cecil et al. [45] \\
PTPRR & Muscle specific expression; deletion causes insulin resistance in \\
SOD1 & mice; key role in pig growth; reduced size in pre-pubertal children & Park et al. 2012 [98] \\
\hline
\end{tabular}



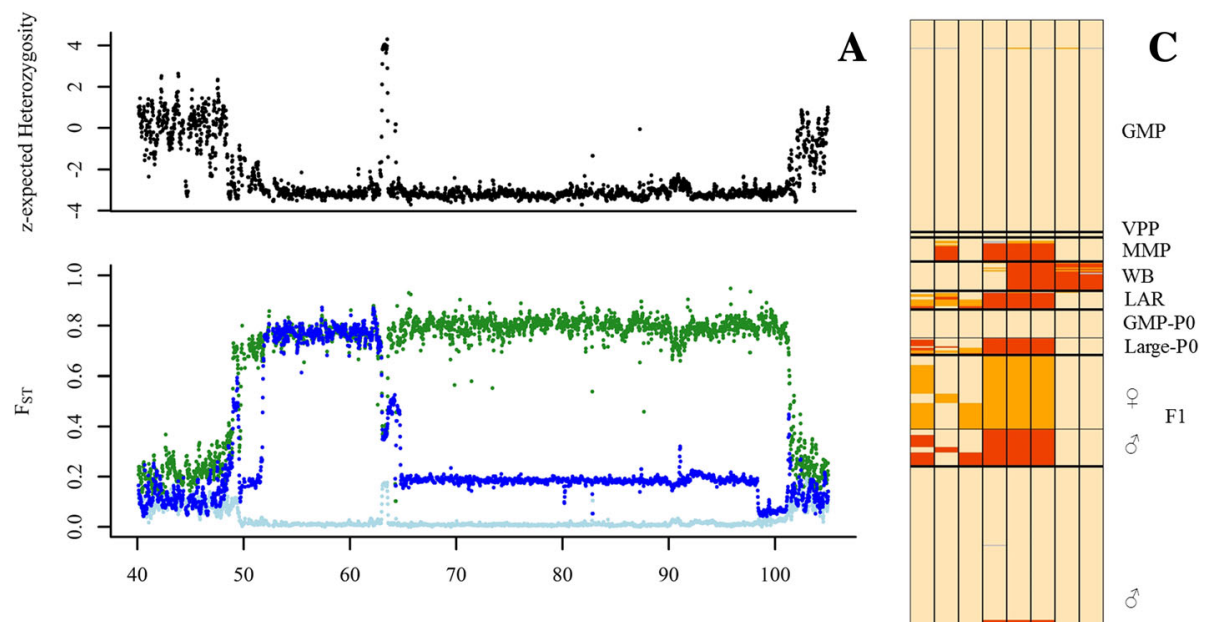

C

B
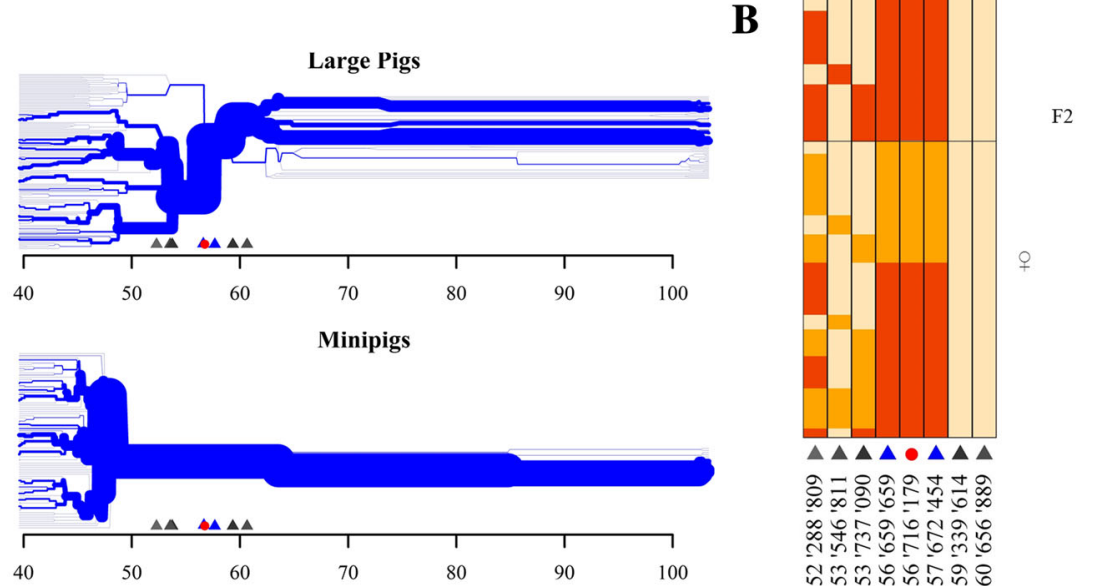

Fig. 3 Large X-chromosomal sweep region, linkage decay and co-located genotypes in cross-bred animals. a Normalized expected heterozygosity in minipigs and fixation index between minipigs and European (green), South Asian (lightblued) and North Asian (darkblue) across the critical region of Chromosome $\mathbf{X}$; b Haplotype breakdown within the major sweep region in all large pig breeds and in the minipig breed respectively, positions in $\mathrm{Mb}$, centered at 56'716'179 Mb; c Allelic state at 8 analyzed SNPs in the sweep region between 50 and $62 \mathrm{Mb}$ (red = homozygous for minipig allele, orange $=$ hemi $-/$ heterozygous, beige $=$ homozygous for opposite allele), positions in bp. Red dot and blue and grey triangles indicate SNP positions; $(q=$ female, $\hat{o}=$ male $)$

center loci perfectly coincide with the affiliation of a pig to the large pigs or the minipigs, respectively (Fig. 3c). We only observed heterozygous genotypes in animals from the cross-breeding experiment. Thus, these markers are fully informative to decide whether a cross-bred animal carries the large pig haplotype or the minipig (South Asian) haplotype in the interval between 52 and $61 \mathrm{Mb}$. The two markers at the end of the interval are homozygous in most European wild boars. Omitting the markers in the beginning of the interval, there are only three clearly distinguishable haplotypes within the sampled breeds in the first region of the selective sweep. Figure $3 \mathrm{~b}$ shows the LD decay, depicted as a bifurcation diagram centered at position $56^{\prime} 716^{\prime} 179$ for both, the large pig haplotype, based on all SNP array genotypes of all large pigs without wild boars and the minipig derived haplotype without Minnesota Minipigs. The minipig derived haplotype is stable over the whole first part of the selective sweep and is barely variable in the second part. The large pig haplotype is less stable and it splits up within the borders of the first sweep region and in the beginning of the second sweep region. The distribution of the haplotypes can be found in Additional file 8.

\section{Inheritance of the haplotypes in cross-bred animals}

Under the assumption of no recombination within the selective sweep region on $\mathrm{X}$ and the cross-breeding scheme of Pant et al. [12], we expected a certain distribution of combinations of these haplotypes in animals of the $F_{1}$ and $F_{2}$ generation. Using the aforementioned SNP loci, we determined which haplotypes were inherited. As shown in Table 3, all $F_{1}$ females should be heterozygous and all males should be hemizygous for the large pig haplotype. In the $F_{2}$, half of the females are expected to 


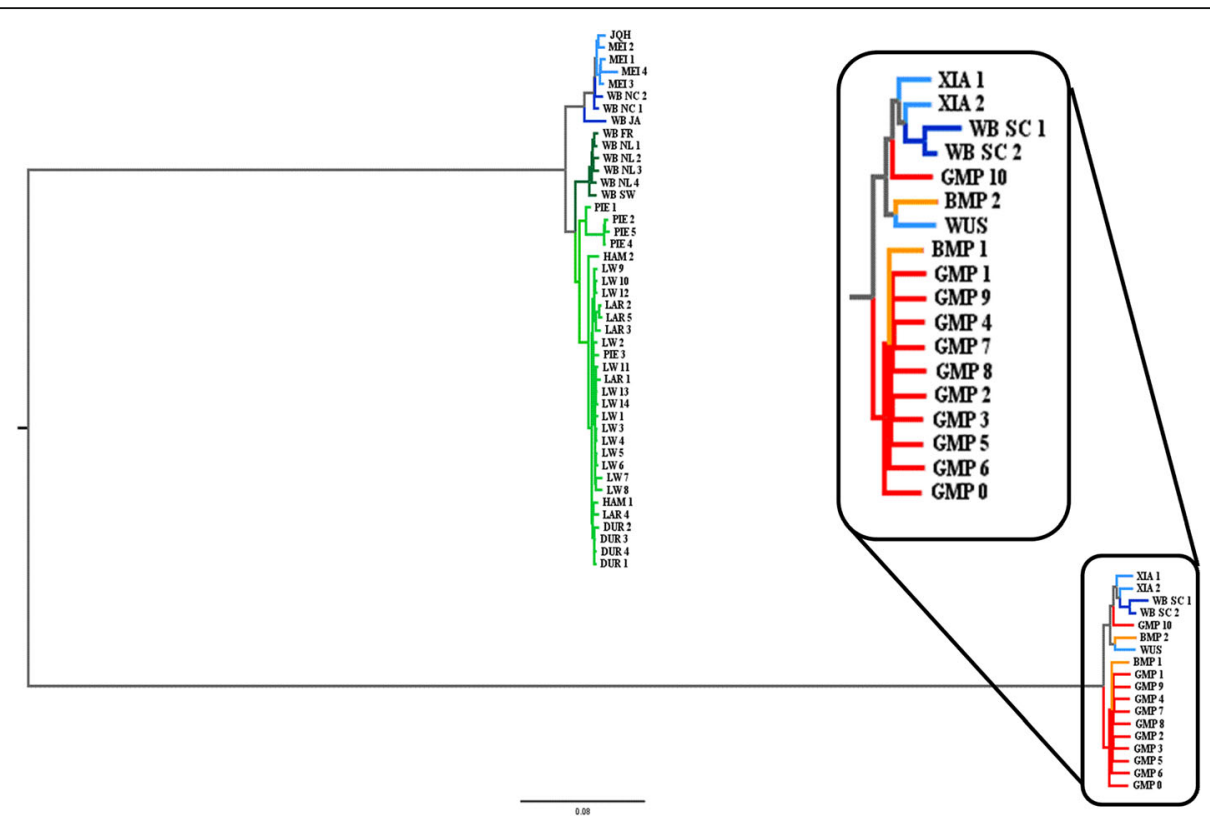

Fig. 4 Neighbor-joining tree for all markers between 52 and $61 \mathrm{Mb}$ on chromosome X. Asian wild boars in dark blue, Asian domestics in light blue, European wild boars in dark green, European domestics in light green, Mini-LEWE in orange and Goettingen Minipigs in red

be homozygous for the large pig haplotype, the other half heterozygous. The $F_{2}$ males should be hemizygous, one half for the minipig haplotype, the other half for the large pig haplotype. The observed haplotypes match the expected Mendelian proportions.

\section{Effect estimators of linear models}

The distribution of phenotypic values of the analyzed traits of height and length at the ages of scanning and slaughtering are displayed in Table 4.

Table 5 shows the covariates considered in the final models for the analysis of the different traits. All non-significant higher interactions were removed from the model. We could not find a significant influence of the haplotype on the length at age of scanning and height at age of scanning, although in the latter, the $p$-value was 0.0718 and the subsequent conservative
LSD test showed significant differences between the haplotypes. Only the sex and the age were important for length at age of scanning. The breed of the mother in the $\mathrm{P}_{0}$ did not influence the size traits of young animals at age of scanning. Figure 5 shows the estimated effects of the inherited X-chromosomal haplotype on the traits "height at slaughter" and "length at slaughter".

For the two traits, where the haplotype effect was significant, males carrying an X-chromosome copy inherited from the minipig ancestor were significantly smaller than the ones carrying the large pig copy, while there was no significant size difference between homozygous females of large pig origin and the heterozygous females.

The respective violin plots of the linear predictors, which can be interpreted as corrected phenotypes for the four haplotype"sex classes, show a clear distinction of the males by haplotype origin.

Table 3 Theoretical inheritance of the two segregating haplotypes on the X-chromosomes in the cross-bred pigs

\begin{tabular}{|c|c|c|c|c|c|c|c|c|c|}
\hline $\mathbf{F}_{1}$ & $\partial x$ & $\mathrm{n}$ & $\widehat{\partial} y$ & $\mathrm{n}$ & $\mathbf{F}_{2}$ & $\delta^{\lambda} X$ & $\mathrm{n}$ & $\delta^{\hat{y}}$ & $\mathrm{n}$ \\
\hline \multirow[t]{2}{*}{$q \mathrm{X}$} & $9 \mathrm{Xx}$ & & $\delta^{\Uparrow} \mathrm{Xy}$ & & $q_{\mathbf{X}}$ & $o_{x X}$ & 90 & ठैxy & 114 \\
\hline & & 28 & & 55 & & & & & \\
\hline$q X$ & $q X x$ & & $\delta^{\top} \mathrm{Xy}$ & & $q X$ & qXX & 129 & ${ }^{7} \mathrm{Xy}$ & 114 \\
\hline
\end{tabular}


Table 4 Sample size, average age, means and standard deviations for the analyzed traits in $F_{2}$ cross-breds

\begin{tabular}{lllll}
\hline Trait & $\mathrm{N}$ & Age [days] & Mean $[\mathrm{cm}]$ & SD $[\mathrm{cm}]$ \\
\hline Height at scanning & 432 & $63(45-166)$ & $39.93 \pm 0.21$ & 4.39 \\
Height at slaughter & 263 & $242(166-439)$ & $65.30 \pm 0.31$ & 5.05 \\
Length at scanning & 432 & $63(45-166)$ & $48.56 \pm 0.28$ & 5.91 \\
Length at slaughter & 410 & $242(166-439)$ & $84.16 \pm 0.31$ & 6.21 \\
\hline
\end{tabular}

\section{Genes inside the sweep}

We found 18 known genes lying within the first sweep region on chromosome $X$ (Additional file 9). One of those is the androgen receptor gene $A R$, which has several functions in physiological processes related to growth, body conformation and reproduction. Besides its crucial role in spermatogenesis and male fertility [13, 14], it is involved in spinal muscle atrophy [15], bone growth [16] and in the determination of body size in humans, where a mild supply of testosterone to boys of under-average size stimulated growth and sexual development without compromising final height [17]. It is located in a large QTL for pig performance and carcass traits [18] and has been identified as a candidate underlying this QTL [19]. Mice with a knock-out of the $A R$ suffer a late onset of obesity while being normally sensitive to insulin [20]. Additionally $A R$ is activated by the growth factors $I G F, K G F$ and EGF in tumors [21].

\section{Discussion}

This is the first study using whole genome resequencing to discover signatures of selection for body size comparing minipigs against individual and pool data of various pig breeds. Direct comparison of contrast, made up from various pig breeds each, mainly differentiated in body size only, appeared as a powerful approach to determine the genetic background of growth and size in minipigs. The high informational density of the next-generation-sequencing data promised deeper insights as the array based approaches before.

\section{SNP calling}

One of the often discussed issues for the quality of WGS studies is the quality of the alignment and the depth at which samples have been sequenced. The proportion of aligned reads to the current reference genome of a Duroc [7] was roughly $90 \%$ for GMP and $87 \%$ for BMP, similar to the proportion we find in European and Asian domestics and confirms Frantz et al. [22] findings when mapping the WGS data of Asian wild boars (Sus verrucosus) against the Duroc reference. When the de novo assembled GMP genome with a length of $2.44 \mathrm{~Gb}$ [23] was mapped against the Duroc reference of $2.3 \mathrm{~Gb}$, about $96 \%$ could be placed on chromosomes. Therefore, using the Duroc reference genome to evaluate minipig genomes appears appropriate, although there is an inherent risk of missing out important parts of the genome.

The number of discovered SNPs in a genome depends on the sequence identity between the reference genome and the examined samples, which is in turn dependent on the phylogenetic distance, the variation inside the breeds and the number of individuals. Additionally, the reliability of calling SNPs and determining genotypes from WGS data is also dependent on the sequencing depth, where for example, reliable calling of a homozygous (heterozygous) SNP requires 15X (30X) coverage [24]. From this point of view, the coverage of all minipigs was sufficient for SNP detection, but proper genotype assignment could be improved by resequencing at higher depth.

\section{Phylogeny}

Analysis of the genetic distance and $\mathrm{F}_{\mathrm{ST}}$ of the sequenced animals showed a clear differentiation between European and Asian pig breeds. This result is in agreement with the current scientific consensus, that domestication occurred independently in Europe and Asia around 9000 years ago [10]. In contrast to European breeds which evolved straight from the wild boar [25], the history of Asian pigs is more complex: After dispersal into the islands and Oceania, interrupted by feral states, pigs were eventually transferred to the Asian mainland [26]. Later, the Chinese populations diverged into a northern and a southern strain [11]. Our results confirm the gap between south Chinese (Xiang, Wuzhishan) and north Chinese domestic breeds (Jiangquhai, Meishan) but appear less clear than in Ai et al. [11].

In the phylogenetic tree, the Goettingen and the Mini-LEWE are located between the Asian and the European cluster. Looking at the breed histories, both breeds are synthetic crosses of the Vietnamese Potbellied Pig with European breeds. In the case of the Mini-LEWE, the crossing partner was the Saddleback pig and "Deutsches

Table 5 Factors with significant influence on growth traits

\begin{tabular}{llllllll}
\hline Trait & Breed & Sex & Age & Age $^{2}$ & Haplotype(Sex) & Breed $^{*}$ sex & Breed Age $^{*}$ Breed*Age $^{2}$ \\
\hline Length at age of scanning & & 0.003 & 0.016 & $<0.0001$ & & & \\
Height at age of scanning & & 0.29 & 0.057 & $<0.0001$ & 0.072 & 0.003 & 0.060 \\
Length at age of slaughter & 0.102 & 0.004 & 0.008 & & 0.0004 & 0.031 & 0.025 \\
Height at age of slaughter & 0.038 & 0.005 & 0.593 & 0.543 & 0.0014 & & 0.031 \\
\hline
\end{tabular}



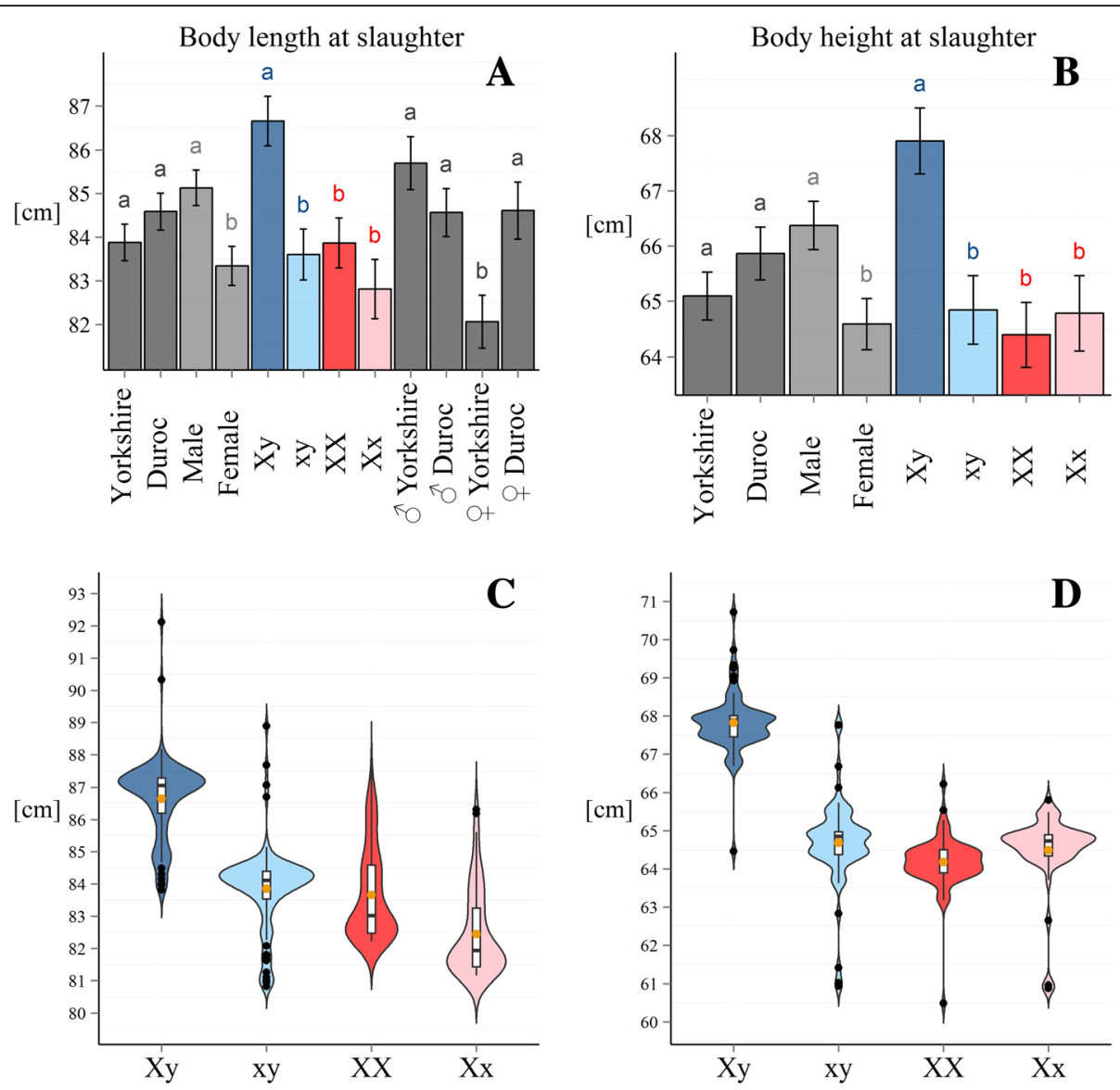

Fig. 5 Estimated effects of the X-chromosomal haplotype state on body size. $\mathbf{a}$ and $\mathbf{b}$ Least-square means for the significant effects for traits length and height at slaughter. $\mathbf{c}$ and $\mathbf{d}$ Violin plots of phenotypes, corrected for all significant covariates, apart from haplotype/ sex for the respective traits

veredeltes Landschwein" (comparable to Large White) [27]. The GMP was established using German Landrace and the Minnesota Minipig [5], itself a cross bred of five breeds of not completely resolved but mostly north American feral, possibly Asian origin [28]. This might be the reason for the BMP being closer to the European cluster than the GMP.

\section{Signatures of selection}

\section{Polygenic effect of autosomal genes on growth}

This study compares two contrasting groups in order to reveal the genetic background of the reduced body size: various large pig breeds from all over the world versus a group of two minipig breeds. Such a study design has been proven efficient before in detecting regions of differentiating selection before in chicken [29] and pigs [8] and has revealed comprehensive sets of candidate genes in both studies. Although it is known that low recombination rates in combination with inbreeding have the potential to produce signatures similar to selective sweeps [30], the inclusion of two genetically highly diverged minipig breeds should attenuate this problem.
We discovered numerous putative sweep regions containing a comprehensive gene set and a first conclusion could, therefore, be that the genetic background of size differentiation is rather polygenic than mono- or oligo genic. This is not surprising, since it is known for other vertebrate species like humans [31] and chicken [32] that growth has a polygenic background. The consecutive analysis of over-representation for the respective gene ontologies provided a similar picture. A variety of ontologies reached significance, comprising ontologies with functions related to growth traits and energy metabolism, like "mitochondrion" and "positive regulation of growth". The most potentially enriched ontology was ' $\mathrm{Z}$ disc', referring to a structural element of the muscle. The overrepresentation of genes related to mitochondria suggests that the energy metabolism might be a key element for growth restriction in minipigs. Some of the genes in enriched ontologies are known to have direct effects on growth and size development or even dwarfism: A COMT variant increases the risk of having children with reduced birth weight [33], knock out of TPST2 or PATZ1 leads to growth retardation in mice [34, 35]. 
A former study by Gaerke et al. [6] on the same GMP stock using a $60 \mathrm{k}$ SNP array came to similar results. They also discovered numerous regions under putative selection comprising several genes with known effect on growth and suggested a pathway connecting SOCS2, GRB10 and IGF1 as potential cause of small body size in minipigs. This finding supported the hypothesis of Simianer and Köhn [3], that the minipig experiences a form of pituitary dwarfism, comparable to Shetland pony and Dexter cattle, supposedly caused by a deficiency of IGF1. This hypotheses seems natural, since the effect of IGF1 on growth in, for example, Pygmies [36] is known for long. In case of a mutation in an IGF gene, a signature of selection would be expected around the respective gene as it was found in dogs, where small breeds carry a unique coding sequence of IGF1 [37]. However, using WGS data, we did not observe striking signals of selection near any of the known IGF genes or receptor loci. This coincides with findings of Zenobi et al. [38] who concluded that the size difference between normal sized and minipigs is neither related to serum levels of IGF1 or IGF2, nor to a missing response to or reduced secretion of growth hormones. Reduced transcription, manifested in low transcription levels of the IGF genes or other growth hormones, could be ruled out and alterations in the underlying genes seem unlikely. But still the insulin growth factor signaling cascade is a widely considered key mechanism for growth. Our results suggest an alternative function: A possible mechanism behind the dwarf phenotype could be a resistance of the target tissues to insulin. Symptoms of this, i.e. a hampered blood glucose clearance after insulin stimulation, which could be facilitated by a disordered lipid metabolism [39] or an intrauterine growth restriction [40] have been found in a feeding trial with Goettingen Minipigs [41]. Focusing on the breeds used in the cross-breeding for GMPs, the Vietnamese Potbellied Pig was the smallest, but also the most obese one [5]. Even after generations of closed breeding, the major part of the GMP genome can be attributed to the VPP [6], suspected to be the origin for the genetically determined tendency to obesity of current GMPs. The detected signatures of selection contained genes either directly influencing insulin resistance or traits such as obesity or muscle fiber composition. Among these genes PPARG is an outstanding candidate, having direct effects on insulin resistance [42] and muscle fibers [43]. Furthermore its effect on growth has been proven before in humans and pigs $[44,45]$.

Another kind of proportional dwarfism is caused by growth hormone $(G H)$ deficiency [46] which resembles the phenotype of the "Laron dwarfism", that is accompanied by severe growth retardation and obesity [47]. GH is also secreted in the pituitary gland and it was recently communicated that a knock-out of the growth hormone receptor gene GHR using genome editing technology led to further miniaturization of a bama minipig at $15 \mathrm{~kg}$ maturity weight [48]. However, focusing on genes belonging to $G H$ or its receptor genes, we find only the CLR test to show increased evidence of selection about $1 \mathrm{Mb}$ away from $G H R$, but no sign of differentiation between the large and the minipig group. Therefore our results do not support the hypothesis that selection on one of the GH genes is underlying the minipig dwarfism.

Among the detected genes are also genes known to be involved in the mitogen activated protein kinase pathway (MAPK) that controls cell proliferation and differentiation. Klingseisen and Jackson [49] report that this pathway plays a prominent role in growth processes and in the primordial dwarfism. This form of dwarfism leads to a proportional growth restriction causing a phenotype similar to the pituitary dwarfism. Besides others, we found the central gene of the Ras/MAPK pathway MAPK1 in one of the largest sweep regions and MAPKAPK3, located in a large sweep on chromosome 13, which is known to be involved in the mediation of growth inhibiting signals [50] and has been found differentially expressed in the pituitary gland between the large and miniature strain of the Diannan pig [51].

\section{Major effect of the $X$ chromosomal sweep}

The porcine X-chromosome carries a selective sweep of outstanding extent [8]. Using the Chinese Wuzhishan genome reference, Ai et al. [11] located this region of $48 \mathrm{Mb}$ within the borders of 44 to $91.5 \mathrm{Mb}$, which corresponds to the region 52 to $100 \mathrm{Mb}$ on the Duroc reference that we identified as a selective sweep exhibiting low expected heterozygosity in minipigs. We conclude from the same size of the region, the inclusion of partly the same samples in both studies and the nearly completely conserved haplotypes in our SNP chip analysis, that these two regions are analogous to each other. A sweep of comparable physical size was not found in recent selection signature studies in horse [52], sheep [53], chicken [29], dogs [54] or rabbits [55], suggesting that this region might carry vital genetic variations kept together due to haplotype effects or that recombination in the region is suppressed. Ai et al. [11] found a recombination breakpoint between a $14 \mathrm{Mb}$ and a $34 \mathrm{Mb}$ stretch, leading to three major groups of haplotypes, a European, a Southern Chinese and a Northern Chinese recombined haplotype. They explained the high differentiation of these three haplotypes with an introgression from a common ancestor even before domestication followed by a strong selective pressure for habitats in high altitudes. They concluded that this large region remained consistent over long time, since the estimated low recombination rate in this region could facilitate larger sweeps [56]. They speculated that the reason for decreased variation was an enrichment of $\operatorname{poly}(\mathrm{T})$ sequences leading to a reduced 
recombination rate as known from human genomes [57]. Using the Duroc reference for the analysis of our resequencing data, we find that the minipigs carry a haplotype similar to the South Asian samples we employed. This haplotype could be identified as the formerly known southern Chinese haplotype [11], based on the Wuzhishan samples considered in both studies. The SNP chip data within the first sweep region (52-61 Mb) shows that the founder breeds must have provided both the European and the South Asian haplotype into the GMP during breed establishment: The Vietnamese Potbellied Pig carries the South Chinese haplotype, while the Landrace carries the haplotype found in European wild boars and the Minnesota Minipigs carries both haplotypes. Thus it is surprising that we can solely detect the South Chinese haplotype in our current GMP stock, suggesting that the European haplotype must have disappeared during breed consolidation. Since the GMP was always selected for small size and high fertility, these two traits might underlie the selection against the European haplotype.

The subsequent evaluation of an F2 generation from a GMP x Yorkshire and a GMP x Duroc cross for four body size traits showed that males inheriting the GMP haplotype were significantly smaller than a male carrying the European haplotype for three of the four traits, while there was no significant effect on the fourth trait (Length at scanning). These results confirm that the analyzed region carries an allele influencing body size. Due to the cross-breeding scheme no females carrying only the minipig haplotypes on both chromosomes were available. The lack of a significant differentiation between females carrying the large pig haplotype on both copies of the chromosome $\mathrm{X}$ and heterozygous females indicates that the large pig haplotype could carry an allele that is dominant over the allele of the minipig haplotype covering the effect of the GMP allele, even though another study [58] found that the respective minipig allele of the androgen receptor AR, located in this haplotype, was dominant over a Duroc derived copy It also could be due to the mosaic nature of the X-chromosomal activation pattern in female eutherians [59]. At the single cell level, half of the body cells are deemed to carry either an active copy of the large haplotype or the GMP haplotype. Therefore, cells carrying the large pig haplotype might attenuate the size decreasing effect of the cells carrying the GMP copy.

The differences of $3.5 \%(3 \mathrm{~cm})$ in body length at the age of slaughtering and $4.4 \%(3 \mathrm{~cm})$ in height at age of slaughtering are QTL effects of considerable magnitude. Reviewing other QTL studies on size, height and growth shows that the underlying QTL architecture can be highly different dependent on trait or organism. Whereas, in humans, height is a highly heritable trait, influenced by at minimum 180 genetic loci [31] and SNP effects explain up to $45 \%$ of the phenotypic variance [60], only a small portion could be attributed to QTLs. Gudbjartsson et al. [61] identified 27 QTL explaining only 3.7\% of the population variance in height, composed of single effects of about 0.3 to $0.6 \mathrm{~cm}$, which was confirmed by other studies (Visscher [62]: 0.4 to $0.8 \mathrm{~cm}$ average effect size for a QTL; Hirschhorn and Lettre [63]: 0.3 to $0.6 \mathrm{~cm}$ effect on adult height). In domestic animals, larger QTL effects have been found. Signer-Hasler et al. [64] reported that two QTL together explain $18.2 \%$ of the heritable genetic variation in horses $(\sim 0.5 \mathrm{~cm}$ and $\sim 1 \mathrm{~cm}$ for height at withers, respectively). They suggest the higher efficiency of QTL studies in domestic animals compared to humans to be due to the existence of isolated populations with reduced heterogeneity. In a cattle cross breeding scheme, a QTL next to PLAG1, CHCHD7 and MOS was found with an allele substitution effect of $2 \mathrm{~cm}$ height at withers [65]. Rubin et al. [8] found that genotype combinations at two loci, $L C O R L$ and PLAG1, together explained a difference of $5.3 \mathrm{~cm}$ in body length in domestic pigs. Since we could not find signals of selection neither at LCORL nor PLAG1 in our study, it is noticeable that the effect size of the chrX locus described herein has a similar effect size. Among the genes located in this region, the androgen receptor appears to be the most prominent candidate for a gene underlying the growth differences between pigs carrying opposite haplotypes. $A R$ is influenced by several growth factors [21], has known function in growth processes $[16,17]$ and underlies the obesity phenotype that is commonly found in minipigs $[20,66]$. Another study on the effect of the $A R$ [19] on performance and carcass traits based on a cross-breeding experiment made up with Duroc and MiniLEWE also found that Duroc and MiniLEWE carry different copies of the $A R$. It could be shown that the MiniLEWE allele led to higher expression of the $A R$ in several tissues including the uterus, and had effect on several performance and carcass traits. The haplotype that contains $A R$ carried by all studied GMP was most likely identical to the aforementioned MiniLEWE allele and introduced by the Vietnamese Potbellied Pig during breed foundation. This pig breed was originally not only chosen for its small size, but also for the much higher litter size compared to the Minnesota Minipig [5]. Since there is a correlation between body size and litter size in mammals [67], which Ferguson et al. [68] estimated to be $r=0.2$ in pigs, the current breeding scheme for low body weight and high fertility might have favored the Asian haplotype and $A R$ seems to be one of the underlying causal genes for the miniature body size.

\section{Conclusion}

Comparison of WGS data of minipigs against data of various large pig breeds is a logical approach in order to reveal the genetic background of body size in pigs. Signature of selection analysis with multiple complementary methods 
provided a comprehensive set of putative sweep regions, spanning approximately $2 \%$ of the autosomal genome. The set of associated genes and the consecutive GO term overrepresentation analysis suggest that energy metabolism, alterations in central elements of the MAPK pathway, and a possible insulin resistance might play a role in body size inheritance of miniature pigs. Additionally, the density of resequencing data proved to be especially useful to analyze a large sweep region on chromosome $\mathrm{X}$, since the SNP chip available so far holds just few SNPs of limited information in that region. We identified three SNPs on the genotyping chip, serving as perfect markers to determine the respective haplotypic state of an individual in future studies. The effect size of the QTL of $3 \mathrm{~cm}$ in body length and height underlying this selective sweep is comparable to the largest QTL for body size traits known from other studies in mammals.

\section{Methods}

\section{Analysis of whole genome resequencing data} Samples and raw data preparation

We extracted DNA from 10 representative contemporary GMP sows from the experimental herd of the University of Goettingen. DNA from 2 Mini-LEWE (BMP) sows, a miniature breed developed in Berlin, Germany and a DNA-pool of 10 female BMPs from the University of Veterinary Medicine Hannover was also prepared. Whole genome re-sequencing was performed at the Science for Life laboratory at Uppsala University, Sweden on an Illumina HighSeq2000 as paired end sequencing with an aimed average sequencing depth of $12 \mathrm{X}$. The raw sequencing data is deposited in ENA under project accession PRJEB27654.

We added Publicly available re-sequencing data underlying the studies of Rubin et al. [8], Fang et al. [9] and Vamathevan et al. [23]. These samples contained breeds of Asian and European origin, both domestic and wild, and comprised animals of the breeds Duroc (DUR), Hampshire (HAM), Jiangquhai (JQH), Large White (LW), Landrace (LAR), Meishan (MEI), Pietrain (PIE), Xiang (XIA), European wild boars (WB FR, WB NL, WB SW), Asian wild boars (WB SC, WB NC, WB JA), a Wuzhishan (WUS) and one Goettingen Minipig (GMP) (Additional file 10).

We aligned all sequence reads to the reference genome susScrofa3 (build 10.2; [7]) using the Burrows-Wheeler algorithm as implemented in the software bwa [69]. The read trimming parameter was set to $q=5$. We then sorted the alignments with Samtools [70] and used Picard tools [71] to mark duplicates without removal, to down-sample the data of the single Goettingen Minipig to a coverage comparable to the other minipig individuals and to construct indices for the alignments. Single Nucleotide Polymorphisms (SNPs) were called with GATKs Unified Genotyper [72, 73].
In order to obtain a reliable dataset for the selective sweep analysis, we applied a stringent filtering process on the variant call set, by first removing InDels and multi-allelic SNPs and filtering with GATK for a comprehensive set of quality criteria described in the methods section. The filters for chromosome $\mathrm{X}$ were adjusted separately taking into account the reduced depth of this chromosome in males. In addition, to keep a sample record a minimum genotype quality (GQ) of 20 was required for sequenced individuals and a minimum depth of coverage of 4 was required for pools.

\section{In-silico pooling}

For further analyses we constructed two contrasting in-silico pools: the large pig virtual pool (LPP) made up of Duroc, Hampshire, Jiangquhai, Large White, Landrace, Meishan, Pietrain, the European wild boars and the Asian wild boars. The minipig in-silico pool (MPP) comprised the Goettingen Minipigs, the Mini-LEWE and the Mini-LEWE-pool. For this, we calculated the reference allele frequency per breed for each locus. For each called SNP, the reference allele frequency in each in-silico pool was then calculated as the unweighted average of the respective breed reference allele frequencies. SNP loci for which less than $50 \%$ of the breeds in one of the two groups had a record were excluded.

\section{Selection signature detection}

For the detection of genomic regions with influence on the small size of the minipigs, we calculated heterozygosity and $F_{S T}$ with custom R scripts [74] and combined it with the composite likelihood ratio (CLR) test, implemented in SweepFinder [75].

We calculated expected heterozygosity per locus as $H_{\text {exp }}=2 p(1-p)$ where $p$ is the reference allele frequency in the MPP and afterwards averaged it in sliding windows of $100 \mathrm{~kb}$ with $80 \%$ overlap. We then normalized the $H_{\text {exp }}$ values of individual windows into Z-scores by adjusting the value using the mean and standard deviation derived from all $100 \mathrm{~kb}$ windows along autosomes and the $\mathrm{X}$-chromosome independently. We defined candidate selective sweeps using an outlier approach whereby a window that fell below a value of -2.34 (lowest $1 \%$ ) was required to initially call a sweep, such sweeps were then extended to each side until values exceeded -1.64 (lowest $5 \%$ ).

The CLR test [75], implemented in SweepFinder was applied to the same $100 \mathrm{~kb}$ windows of the filtered SNP data of all individuals belonging to the Goettingen Minipigs and the Mini-LEWE. We excluded invariable loci across both groups and took the highest $1 \%$ of the signals further analysis.

The differentiation between the LPP and the MPP was determined by the fixation index 


$$
F_{S T}=\frac{\sum n_{i}\left(p_{i}-\bar{p}\right)^{2} /(2 \bar{n})}{\bar{p}(1-\bar{p})}
$$

altered after [76], where $p_{i}$ is the frequency of the reference allele in group $i, \bar{p}$ is the weighted mean frequency of the first allele in both groups, $n_{i}$ is the number of samples within a group $i$, and $\bar{n}$ is the average group size. We averaged the values across the same windows of $100 \mathrm{~kb}$ with $80 \%$ overlap as for heterozygosity and detected regions of increased differentiation by the same method as used for expected heterozygosity, with the highest $1 \%$ and $5 \%$ of the actual values taken as thresholds.

A selective sweep was assumed, when regions showed decreased expected heterozygosity in the minipig or when the composite likelihood ratio test overlapped with signals of high differentiation between the two groups. We required a minimum width of $200 \mathrm{~kb}$ and extended the final regions by $0.5 \mathrm{Mb}$ to each side. Figure 6 shows the proportions of the autosomes detected to be under putative selective pressure. The CLR test detected 1\% of the genome as putative sweeps of which 59\% intersected with outstanding $\mathrm{F}_{\mathrm{ST}}$ signals. The heterozygosity signature method found $5.3 \%$ of the genome to be under selection, $\sim 30 \%$ thereof (1.6\% of the genome) intersecting with extreme $\mathrm{F}_{\mathrm{ST}}$ signals. $0.3 \%$ of the whole genome was shared between CLR and heterozygosity signature. Finally, we used the union of CLR and expected Heterozygosity signals intersecting with $\mathrm{F}_{\mathrm{ST}}$ for further analysis.

\section{Phylogeny}

We constructed phylogenetic trees from biallelic SNPs, extracted from filtered VCF-files with VCFtools [77] and from array data with customized R-code. We calculated the pairwise distance with Plink [78] as 1 - similarity between samples, where similarity was the proportion of a genome of an individual being identical by state (IBS) with another animal's genome. Based on this, we constructed the neighbor joining tree using PHYLIP [79]. We estimated pairwise $F_{S T}$ values from all autosomal SNP loci with $90 \%$ or more animals with genotypes that passed filters. This was done in each contrasting combination of the individual data of European breeds, Asian breeds and minipigs and for the subgroups European domestic breeds, European wild boars, Asian domestics, Asian wild boars, Goettingen Minipigs and Mini-LEWE, respectively (additional information on the groups can be found in Additional file 2 and Additional file 3). Subsequently, we averaged values at all loci to gain a genome wide $F_{S T}$ value.

\section{Gene annotation and gene overrepresentation analysis}

We annotated genes within regions of interest using the Ensembl Pig Gene set 79 [80] and, subsequently, conducted a gene ontology $(\mathrm{GO})$ overrepresentation analysis by using Fisher's exact test [81]. We calculated fold enrichment $F E$ as

$$
F E=\frac{a}{\frac{(a+b)(a+c)}{a+b+c+d}},
$$

with $a$ being the number of genes within a sweep and the respective gene ontology, $b$ being the number of genes within a sweep but outside the respective gene ontology, $c$ being the number of genes in a respective gene ontology but outside a sweep and $d$ being the number of genes outside a sweep and outside the respective gene ontology $[82,83]$. All statistics were applied on all GO terms for which genes had been found within a putative selective sweep. To account for possible bias resulting from assumption violations of the Fisher's exact test (e.g. independency

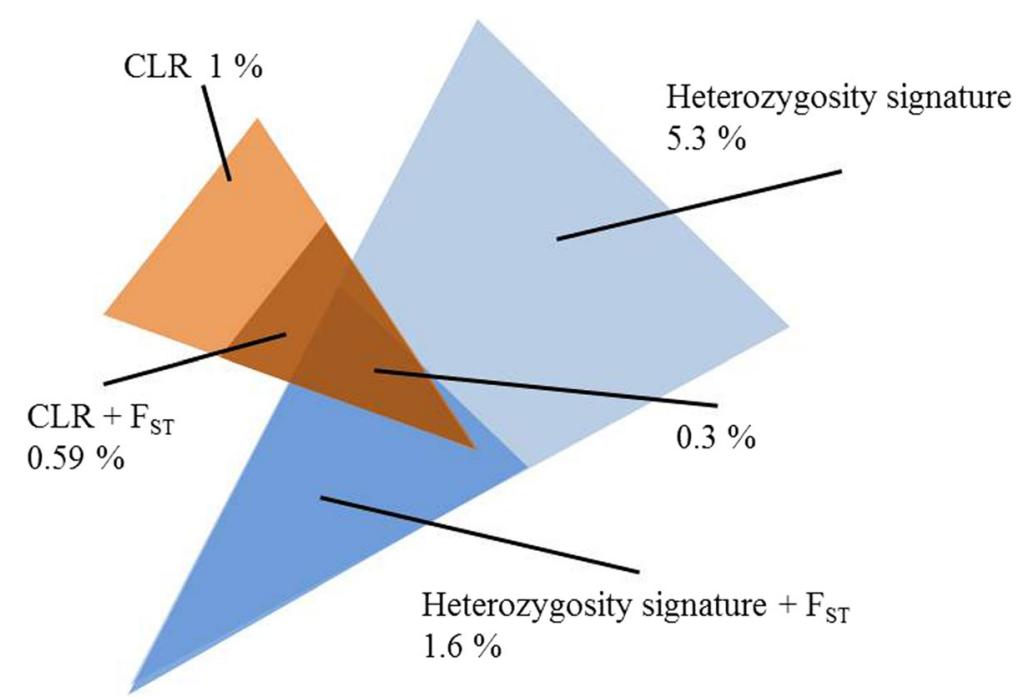

Fig. 6 Overlaps between selection signature detection methods 
of the genes) as well as the multiple testing problem, we conducted a permutation analysis to construct empirical significance thresholds for the calculated $p$-values. To this end, we shifted the set of sweep regions along the genome by a random number of base pairs between 1 and the genome length, while retaining sweep sizes. Genes were then annotated to the shifted set of sweep regions and Fisher's exact test $p$-value was re-estimated for each ontology term found in our original annotation. This random shifting should assure the resulting $p$-values to reflect the case when the null hypothesis is true. Based on 5000 replications, the $5 \%$ quantile threshold was taken to determine the significance threshold for each gene ontology term.

Independent validation of a major sweep on the X-chromosome For a large sweep region in the middle of chromosome $\mathrm{X}$, we used additional SNP array genotype data and phenotypic data from two other studies [6, 12] for a more comprehensive examination of this region and its effect on growth.

The samples from [6] comprised 154 GMP, 11 MMP, 4 VPP, 16 European WB and 11 LAR. Pant et al. [12] conducted an F2 cross-breeding experiment in which Duroc and Yorkshire females, respectively, were crossed with Goettingen Minipig males. This study provided X-chromosomal genotypes of 21 GMP males, 6 Duroc and 7 Yorkshire females, $83 \mathrm{~F}_{1}$ animals and $454 \mathrm{~F}_{2}$ animals. All samples were genotyped with the Illumina PorcineSNP60 BeadChip. Size phenotypes for the $F_{2}$ animals were also provided.

SNPs within the region of interest, 52 to $61 \mathrm{Mb}$ on the $\mathrm{X}$-chromosome were identified. We used Plink [78] to filter out individuals with more than $90 \%$ missing genotypes and SNPs with less than $90 \%$ genotyping rate or a minor allele frequency of less than $1 \%$. Under the assumption of no recombination between the haplotypes of the European, Asian and minipig breeds we searched for loci being fixed within a group but showing different states between groups. We then used such informative SNPs to determine the origin of the two haplotypes in the $\mathrm{F}_{2}$ animals.

Based on the results of the sequence-based analysis, we hypothesized that the origin of the haplotype in the considered region should affect the body size of $F_{2}$ animals. We therefore classified $F_{2}$ animals in three groups: Homozygous females or hemizygous males carrying the Duroc/ Yorckshire haplotype as first class, heterozygous females as the second class and hemizygous males carrying the minipig haplotype as the third class. These classes were subsequently modeled as a fixed effect nested within sex.

Effects of the minipig haplotype on the four phenotypical traits "shoulder height at slaughter", "body length at slaughter", "shoulder height at age of scanning" and "body length at age of scanning" were estimated using proc. "mixed" from SAS 9.4 [84]. The full model was

$$
\begin{aligned}
y_{i j k}= & B_{i}+S_{j}+b_{1} A_{i j}+b_{2} A_{i j}^{2}+H_{k}\left(S_{j}\right)+B_{i} \times S_{j} \\
& +b_{3}\left(B_{i} \times A_{i j}\right)+b_{4}\left(B_{i} \times A_{i j}^{2}\right)+B_{i} \times H_{k}\left(S_{j}\right) \\
& +b_{5}\left(A_{i j} \times H_{k}\left(S_{j}\right)\right) e_{i j k}
\end{aligned}
$$

where $y_{i j k}$ is the dependent variable, $B_{i}$ is the fixed effect of the breed of the female ancestor in the founder generation $(i=1,2), S_{j}$ is the sex, $A_{i j k}$ is the animal's age at measurement in days, $H_{k}$ is the haplotype, either 1 for homozygous females and hemizygous males carrying the large pig haplotype, 2 for heterozygous females and 3 for hemizygous males carrying the minipig haplotype. Each $b_{l}(l=1, \ldots, 5)$ depicts the linear regression coefficient of the age or the respective interaction of a factor with age. $e_{i j k}$ is the residual error. The full model was reduced by stepwise backward selection of factors with the highest $p$-values until only significant factors remained.

We employed the R package "rehh" [85] to estimate the extension of the two haplotypes and the decay of linkage disequilibrium around the central position of SNP 'H3GA0051810' (56'716'179 bp). Genes within this region were annotated with the Ensembl Pig Gene set 79 [80]. Finally QTL [86] known from former studies located in this region were retrieved from the Pig QTL database (Results not shown).

\section{Additional files}

Additional file 1: Figure S1. Multi-Dimensional-Scaling of the distance matrix underlying the phylogenetic tree, based on chromosomes 1, 8 and 13. (DOCX $95 \mathrm{~kb}$ )

Additional file 2: Table S1. Genome-wide estimated FST values between different contrasts of breed groups for all loci with call-rate $\geq 90 \%$, over diagonal, standard errors below diagonal. (XLSX $10 \mathrm{~kb}$ )

Additional file 3: Table S2. Genome-wide estimated FST values between different contrasts of breed groups for all loci with call-rate $\geq 90 \%$, over diagonal, standard errors below diagonal. (XLSX 9 kb)

Additional file 4: Table S3. Putative selective sweeps with genes contained. (XLSX $12 \mathrm{~kb}$ )

Additional file 5: Table S4. Potentially overrepresented GO-Terms in selective sweeps. (XLSX $14 \mathrm{~kb}$ )

Additional file 6: Figure S2. Neighbor-joining tree based on all SNPS in the second part of the selective sweep region on chromosome $X$ between 64 to $96 \mathrm{Mb}$. (DOCX $61 \mathrm{~kb}$ )

Additional file 7: Table S5. Overview of SNPs in the region from 52 to $61 \mathrm{Mb}$ on chromosome $X$, including results of filtering. (XLSX $10 \mathrm{~kb}$ )

Additional file 8: Table S6. Occurring haplotypes in region 52 to $61 \mathrm{Mb}$ on chromosome $X$ and numbers of carrier animals. (XLSX $10 \mathrm{~kb}$ )

Additional file 9: Table S7. Genes located in first region of large sweep on chromosome X. (XLSX 9 kb)

Additional file 10: Table S8. Overview of sampled breeds and descriptive statistics of the re-sequenced samples. (XLSX $10 \mathrm{~kb}$ )

\section{Abbreviations}

BMP: Mini-LEWE; Minischwein Lehnitz-Wendefeld; Chr: Chromosome;

CLR: Composite likelihood ratio test; DNA: Deoxyribonucleic acid; 
DUR: Duroc; ENA: European Nucleotide Archive; GATK: Genome Analysis Toolkit; GMP: Goettingen Minipig; GO: Gene ontology; GQ: Genotype quality; HAM: Hampshire; IBS: Identical by state; JQH: Jiangquhai; LAR: Landrace; LD: Linkage disequilibrium; LPP: Large pig pool; LSD: Least significant difference; LW: Large White; Mb: Mega base pairs, 10^6 base pairs; MEl: Meishan; MMP: Minnesota Minipig; MPP: Minipig pool; PIE: Pietrain; QTL: Quantitative trait loci; SNP: Single nucleotide polymorphism; VCF: Variant call format; VPP: Vietnamese Potbellied Pig; WB FR: Wild boar France; WB JA: Wild boar Japan; WB NC: Wild boar North China; WB NL: Wild boar Netherlands; WB SC: Wild boar South China; WB SW: Wild boar Switzerland; WGS: Whole genome sequencing; WUS: Wuzhishan; XIA: Xiang

\section{Acknowledgements}

The computation was done on the server cluster of the SciLifeLab Compute and Storage (UPPNEX) provided by the Swedish National Infrastructure for Computing (SNIC)

\section{Funding}

We would like to thank Ellegaard Göttingen Minipigs AVS for the financial support of our minipig projects. We would like to acknowledge the SNP\&Seq platform at the Science For Life Laboratory in Uppsala for sequencing the minipig samples. We appreciate the funding by the European Science Foundation within the framework "Advances in Farm Animal Genomic Resources", and by the DAAD U4 network for the stay in Uppsala.

We acknowledge funding from the Independent Research Fund Denmark (DFF-1335-00127) for the F2 crossbred pedigree.

\section{Availability of data and materials}

The various datasets supporting the conclusions of this article are available in the European Nucleotide Archive or Sequence Read Archive and Datadryad: ENA accessions for FASTQ files of samples from Rubin et al. [8]: ERR173170, ERR173171, ERR173172, ERR173173, ERR173174, ERR173175, ERR173179, ERR173180, ERR173181, ERR173182, ERR173183, ERR173184, ERR173185, ERR173186, ERR173187, ERR173188, ERR173189, ERR173190, ERR173191, ERR173192, ERR173193, ERR173194, ERR173195, ERR173196, ERR173197, ERR173198, ERR173199, ERR173200, ERR173201, ERR173202, ERR173204, ERR173205, ERR173206, ERR173207, ERR173208, ERR173212, ERR173213, ERR173214, ERR173215, ERR173216, ERR173217, ERR173218, ERR173219, ERR173220, ERR173221, ERR173222, ERR173223, ERR173224; Wuzhishan Samples from Fang et al. [9]: SRR448575, SRR448588, SRR448589, SRR448591, inititially accessed through ftp://climb.genomics.cn/pub/10.5524/100001_101000/ 100031/reads/; SRA accessions for GMP samples from Vamathevan et al. [23]: SRR578029, SRR578191, SRR578192; ENA accessions for the GMP and Mini-LEWE data: PRJEB27654; F2 cross breeding data from Pant et al. [12]: http://datadryad. org/resource/doi:10.5061/dryad.3ij7f; SNP data from Gaerke et al. [6]: Please send inquiries to tierzucht@agr.uni-goettingen.de.

\section{Authors' contributions}

CR analyzed the data and mainly wrote the manuscript, CR, CJR, HS designed the project and the strategy for the data analysis and were involved in development of the draft, HS financed the GMP sequencing, CR and ARS developed the linear model used for QTL identification on the X chromosome, ARS contributed significantly to the writing of the respective section, NTH suggested the empirical correction of the multiple testing in the $\mathrm{GO}$ term analysis and wrote the respective paragraph, KHW and OD developed the MiniLEWE sampling strategy and provided samples, SW contributed to the conceptualization of the GMP sampling strategy, designed, financed and conducted the DNA preparation and the DNA pooling. MS developed an efficient algorithm for overlapping windows and contributed critically to the draft of the manuscript especially at an early stage. SDP and MF provided, and prepared the X-chromosome data of the cross-bred pigs and applied for the respective funding. All authors read and approved the final manuscript.

\section{Ethics approval and consent to participate}

Goettingen Minipig and MiniLEWE blood samples were obtained within the course of obligatory health screening in the University owned stocks at Research Farm Relliehausen (University of Goettingen) and Forschungsgut Ruthe (TiHo Hannover), conducted by state approved veterinarians.

\section{Consent for publication}

Not applicable

\section{Competing interests}

The authors declare that they have no competing interests.

\section{Publisher's Note}

Springer Nature remains neutral with regard to jurisdictional claims in published maps and institutional affiliations.

\section{Author details}

${ }^{1}$ Animal Breeding and Genetics Group, Department of Animal Sciences, University of Goettingen, Albrecht-Thaer-Weg 3, 37075 Goettingen, Germany. ${ }^{2}$ Science for Life Laboratory, Department of Medical Biochemistry and Microbiology, Uppsala University, Uppsala Biomedicinska centrum BMC, Husargatan 3, 75237 Uppsala, Sweden. ${ }^{3}$ Institute of Farm Animal Genetics of the Friedrich-Loeffler-Institut, Höltystraße 10, 31535 Neustadt-Mariensee, Germany. ${ }^{4}$ Clinic for Swine, Small Ruminants, Forensic Medicine and Ambulatory Service, University of Veterinary Medicine - Foundation, Bischofsholer Damm 15, 30173 Hannover, Germany. Institute of Animal Breeding and Genetics, University of Veterinary Medicine - Foundation, Bünteweg 17p, 30559 Hannover, Germany. ${ }^{6}$ Graham Centre for Agricultural Innovation, School of Animal \& Veterinary Sciences, Charles Sturt University, Locked Bag 588, Boorooma St., Wagga Wagga, NSW, Australia. 'Department of Veterinary- and Animal Sciences, University of Copenhagen, Grønnegårdsvej 3, 1870 Frederiksberg C, Denmark. ${ }^{8}$ School of Business Informatics and Mathematics, University of Mannheim, A5 6, 68131 Mannheim, Germany. ${ }^{9}$ Center for Integrated Breeding Research, University of Goettingen, Albrecht-Thaer-Weg 3, 37075 Goettingen, Germany.

Received: 26 March 2018 Accepted: 14 August 2018

Published online: 19 September 2018

\section{References}

1. Haldane JBS. On being the right size. In: possible worlds. London: Chatto \& Windus; 1927

2. Parker HG, Dreger DL, Rimbault M, Davis BW, Mullen AB, Carpintero-Ramirez $\mathrm{G}$, et al. Genomic analyses reveal the influence of geographic origin, migration, and hybridization on modern dog breed development. Cell Rep. 2017;19:697-708. https://doi.org/10.1016/j.celrep.2017.03.079.

3. Simianer H, Köhn F. Genetic management of the Göttingen Minipig population. J Pharmacol Toxicol Methods. 2010;62:221-6. https://doi.org/10.1016/j.vascn.2010. 05.004.

4. Swindle MM, Makin A, Herron AJ, Clubb FJ, Frazier KS. Swine as models in biomedical research and toxicology testing. Vet Pathol. 2012;49:344-56. https://doi.org/10.1177/0300985811402846.

5. Glodek P, Oldigs B. Das Göttinger Miniaturschwein. Parey: Berlin and Hamburg; 1981.

6. Gaerke C, Ytournel F, Sharifi a R, Pimentel ECG, Ludwig A, Simianer H. Footprints of recent selection and variability in breed composition in the Göttingen Minipig genome. Anim Genet. 2014:381-91.

7. Groenen MAM, Archibald AL, Uenishi H, Tuggle CK, Takeuchi Y, Rothschild $M F$, et al. Analyses of pig genomes provide insight into porcine demography and evolution. Nature. 2012;491:393-8.

8. Rubin C-J, Megens HJ, Martinez Barrio A, Maqbool K, Sayyab S, Schwochow D, et al. Strong signatures of selection in the domestic pig genome. Proc Natl Acad Sci U S A. 2012;109:19529-36. https://doi.org/10.1073/pnas.1217149109.

9. Fang $X$, Mou $Y$, Huang $Z$, Li Y, Han L, Zhang $Y$, et al. The sequence and analysis of a Chinese pig genome. Gigascience. 2012;1:16. https://doi.org/10. 1186/2047-217X-1-16.

10. Giuffra E, Kijas JMH, Amarger V, Carlborg O, Jeon J-T, Andersson L. The origin of the domestic pig: independent domestication and subsequent introgression. Genetics. 2000;154:1785-91.

11. Ai H, Fang $X$, Yang B, Huang Z, Chen H, Mao L, et al. Adaptation and possible ancient interspecies introgression in pigs identified by whole-genome sequencing. Nat Genet. 2015;47:217-25. https://doi.org/10.1038/ng.3199.

12. Pant SD, Karlskov-Mortensen P, Jacobsen MJ, Cirera S, Kogelman LJA, Bruun CS, et al. Comparative analyses of QTLs influencing obesity and metabolic phenotypes in pigs and humans. PLoS One. 2015;10:e0137356. https://doi. org/10.1371/journal.pone.0137356.

13. Chang C, Chen Y-T, Yeh S-D, Xu Q, Wang R-S, Guillou F, et al. Infertility with defective spermatogenesis and hypotestosteronemia in male mice lacking the androgen receptor in Sertoli cells. Proc Natl Acad Sci. 2004;101:6876-81. https://doi.org/10.1073/pnas.0307306101. 
14. Wang R-S, Yeh S, Tzeng C-R, Chang C. Androgen receptor roles in spermatogenesis and fertility: lessons from testicular cell-specific androgen receptor knockout mice. Endocr Rev. 2009;30:119-32. https://doi.org/10. 1210/er.2008-0025.

15. La Spada AR, Wilson EM, Lubahn DB, Harding AE, Fischbeck KH. Androgen receptor gene mutations in $\mathrm{X}$-linked spinal and bulbar muscular atrophy. Nature. 1991;352:77-9. https://doi.org/10.1038/352077a0.

16. Ornoy A, Giron S, Aner R, Goldstein M, Boyan BD, Schwartz Z. Gender dependent effects of testosterone and 17ß-estradiol on bone growth and modelling in young mice. Bone Miner. 1994;24:43-58. https://doi.org/10. 1016/S0169-6009(08)80130-4.

17. Richman RA, Kirsch LR. Testosterone treatment in adolescent boys with constitutional delay in growth and development. N Engl J Med. 1988;319: 1563-7. https://doi.org/10.1056/NEJM198812153192402.

18. Rohrer GA, Keele JW. Identification of Quantitative Trait Loci Affecting Carcass Composition in Swine : I . Fat Deposition Traits. 1998;1:2247-2254.

19. Trakooljul N, Ponsuksili S, Schellander K, Wimmers K. Polymorphisms of the porcine androgen receptor gene affecting its amino acid sequence and expression level. Biochim Biophys Acta - Gene Struct Expr. 2004;1678:94101. https://doi.org/10.1016/J.BBAEXP.2004.02.004.

20. Fan W, Yanase T, Nomura M, Okabe T, Goto K, Sato T, et al. Androgen receptor null male mice develop late-onset obesity caused by decreased energy expenditure and lipolytic activity but show normal insulin sensitivity with high adiponectin secretion. Diabetes. 2005;54:1000-8. https://doi.org/ 10.2337/diabetes.54.4.1000

21. Culig Z, Hobisch A, Cronauer MV, Radmayr C, Trapman J, Hittmair A, et al. Androgen receptor activation in prostatic tumor cell lines by insulin-like growth factor-I, keratinocyte growth factor, and epidermal growth factor. Cancer Res. 1994;54:5474-8.

22. Frantz LAF, Schraiber JG, Madsen O, Megens H-J, Bosse M, Paudel Y, et al. Genome sequencing reveals fine scale diversification and reticulation history during speciation in Sus. Genome Biol. 2013;14:R107. https://doi.org/ 10.1186/gb-2013-14-9-r107.

23. Vamathevan JJ, Hall MD, Hasan S, Woollard PM, Xu M, Yang Y, et al. Minipig and beagle animal model genomes aid species selection in pharmaceutical discovery and development. Toxicol Appl Pharmacol. 2013;270:149-57. https://doi.org/10.1016/j.taap.2013.04.007.

24. Sims D, Sudbery I, llott NE, Heger A, Ponting CP. Sequencing depth and coverage: key considerations in genomic analyses. Nat Rev Genet. 2014;15: 121-32. https://doi.org/10.1038/nrg3642.

25. Scandura M, lacolina L, Crestanello B, Pecchioli E, Di Benedetto MF, Russo V, et al. Ancient vs. recent processes as factors shaping the genetic variation of the European wild boar: are the effects of the last glaciation still detectable? Mol Ecol. 2008;17:1745-62. https://doi.org/10.1111/j.1365-294X. 2008.03703.x

26. Larson G, Cucchi T, Fujita M, Matisoo-Smith E, Robins J, Anderson A, et al. Phylogeny and ancient DNA of Sus provides insights into neolithic expansion in island Southeast Asia and Oceania. Proc Natl Acad Sci U S A. 2007;104:4834-9. https://doi.org/10.1073/pnas.0607753104.

27. Leucht W, Gregor G, Stier H. Einführung in die Versuchstierkunde, Band IV: Das Miniaturschwein - Versuchs- und Modelltier in Medizin und Biologie. Jena. In: Germany: VEB Gustav Fischer Verlag; 1982.

28. Dettmers A. Die Zucht eines neuen Versuchstieres, des Miniaturschweines in Amerika. Zeitschrift für Tierzüchtung und Züchtungsbiologie. 1956;68:37-41. https://doi.org/10.1111/j.1439-0388.1956.tb00617.x.

29. Rubin C-J, Zody MC, Eriksson J, Meadows JRS, Sherwood E, Webster MT, et al. Whole-genome resequencing reveals loci under selection during chicken domestication. Nature. 2010:464:587-91.

30. Bosse M, Megens H-J, Madsen O, Paudel Y, Frantz LAF, Schook LB, et al. Regions of homozygosity in the porcine genome: consequence of demography and the recombination landscape. PLoS Genet. 2012;8 e1003100. https://doi.org/10.1371/journal.pgen.1003100.

31. Lango Allen H, Estrada K, Lettre G, Berndt SI, Weedon MN, Rivadeneira F, et al. Hundreds of variants clustered in genomic loci and biological pathways affect human height. Nature. 2010;467:832-8. https://doi.org/10.1038/nature09410.

32. Jacobsson $L$, Park H-B, Wahlberg P, Fredriksson R, Perez-Enciso M, Siegel PB, et al. Many QTLs with minor additive effects are associated with a large difference in growth between two selection lines in chickens. Genet Res. 2005;86:115. https://doi.org/10.1017/S0016672305007767.

33. Sata F, Yamada H, Suzuki K, Saijo Y, Yamada T, Minakami H, et al. Functional maternal catechol-O-methyltransferase polymorphism and fetal growth restriction. Pharmacogenet Genomics. 2006;16:775-81. https://doi.org/10. 1097/01.fpc.0000230116.49452.c0.

34. Valentino T, Palmieri D, Vitiello M, Simeone A, Palma G, Arra C, et al. Embryonic defects and growth alteration in mice with homozygous disruption of the Patz1 gene. J Cell Physiol. 2013;228:646-53. https://doi.org/ 10.1002/jcp.24174.

35. Sasaki N, Hosoda Y, Nagata A, Ding M, Cheng J-M, Miyamoto T, et al. A mutation in Tpst2 encoding tyrosylprotein sulfotransferase causes dwarfism associated with hypothyroidism. Mol Endocrinol. 2007;21:1713-21. https:// doi.org/10.1210/me.2007-0040.

36. Merimee TJ, Zapf J, Froesch ER. Dwarfism in the pygmy. N Engl J Med. 1981 305:965-8. https://doi.org/10.1056/NEJM198110223051701.

37. Sutter NB, Bustamante CD, Chase K, Gray MM, Zhao K, Zhu L, et al. A single IGF1 allele is a major determinant of small size in dogs. Science. 2007;316: 112-5. https://doi.org/10.1126/science.1137045.

38. Zenobi PD, Guler H-P, Zapf J, Froesch ER. Insulin-like growth factors in the Gottinger miniature-pig. Eur J Endocrinol. 1988;117:343-52. https://doi.org/ 10.1530/acta.0.1170343.

39. Savage DB, Petersen KF, Shulman Gl. Disordered lipid metabolism and the pathogenesis of insulin resistance. Physiol Rev. 2007;87:507-20. https://doi. org/10.1152/physrev.00024.2006.

40. Jaquet D, Gaboriau A, Czernichow P, Levy-Marchal C. Insulin resistance early in adulthood in subjects born with intrauterine growth retardation. J Clin Endocrinol Metab. 2000;85:1401-6. https://doi.org/10.1210/jcem.85.4.6544.

41. Larsen MO, Rolin B, Wilken M, Carr RD, Svendsen O. High-fat high-energy feeding impairs fasting glucose and increases fasting insulin levels in the Göttingen Minipig. Ann N Y Acad Sci. 2006;967:414-23. https://doi.org/10. 1111/j.1749-6632.2002.tb04297.x.

42. Hevener AL, He W, Barak Y, Le J, Bandyopadhyay G, Olson P, et al. Musclespecific Pparg deletion causes insulin resistance. Nat Med. 2003;9:1491-7. https://doi.org/10.1038/nm956.

43. Crooks DR, Natarajan TG, Jeong SY, Chen C, Park SY, Huang H, et al. Elevated FGF21 secretion, PGC-1a and ketogenic enzyme expression are hallmarks of iron-sulfur cluster depletion in human skeletal muscle. Hum Mol Genet. 2014;23:24-39. https://doi.org/10.1093/hmg/ddt393.

44. Puig-Oliveras A, Ballester M, Corominas J, Revilla M, Estellé J, Fernández Al, et al. A co-association network analysis of the genetic determination of pig conformation, growth and fatness. PLoS One. 2014;9:e114862. https://doi. org/10.1371/journal.pone.0114862.

45. Cecil JE, Fischer B, Doney ASF, Hetherington M, Watt $\mathrm{P}$, Wrieden $W$, et al. The Pro12Ala and C-681G variants of the PPARG locus are associated with opposing growth phenotypes in young schoolchildren. Diabetologia. 2005; 48:1496-502. https://doi.org/10.1007/s00125-005-1817-0.

46. Baumann G. Mutations in the growth hormonereleasing hormone receptor: a new form of dwarfism in humans. Growth Hormon IGF Res. 1999;9:24-30. https://doi.org/10.1016/S1096-6374(99)80077-X.

47. Laron Z, Anin S, Klipper-Aurbach Y, Klinger B. Effects of insulin-like growth factor on linear growth, head circumference, and body fat in patients with Laron-type dwarfism. Lancet. 1992:339:1258-61. https://doi.org/10.1016/ 0140-6736(92)91594-X

48. Cyranoski D. Gene-edited "micropigs" to be sold as pets at Chinese institute. Nature. 2015;526:18-8. https://doi.org/10.1038/nature.2015.18448.

49. Klingseisen A, Jackson AP. Mechanisms and pathways of growth failure in primordial dwarfism. Genes Dev. 2011;25:2011-24. https://doi.org/10.1101/ gad.169037.

50. Mayer IA, Verma A, Grumbach IM, Uddin S, Lekmine F, Ravandi F, et al. The p38 MAPK pathway mediates the growth inhibitory effects of interferonalpha in BCR-ABL-expressing cells. J Biol Chem. 2001;276:28570-7. https:// doi.org/10.1074/jbc.M011685200.

51. Yonggang $L$. A novel porcine gene, MAPKAPK3, is differentially expressed in the pituitary gland from mini-type Diannan small-ear pigs and large-type Diannan small-ear pigs. Mol Biol Rep. 2010;37:3345-9. https://doi.org/10. 1007/s11033-009-9921-8.

52. Petersen JL, Mickelson JR, Rendahl AK, Valberg SJ, Andersson LS, Axelsson J, et al. Genome-wide analysis reveals selection for important traits in domestic horse breeds. PLoS Genet. 2013;9:e1003211. https://doi.org/10. 1371/journal.pgen.1003211.

53. Kijas JW, Lenstra JA, Hayes B, Boitard S, Porto Neto LR, San Cristobal M, et al. Genome-wide analysis of the world's sheep breeds reveals high levels of historic mixture and strong recent selection. PLoS Biol. 2012:10:e1001258. https://doi.org/10.1371/journal.pbio.1001258. 
54. Axelsson E, Ratnakumar A, Arendt M-L, Maqbool K, Webster MT, Perloski M et al. The genomic signature of dog domestication reveals adaptation to a starch-rich diet. Nature. 2013;495:360-4. https://doi.org/10.1038/nature11837.

55. Carneiro M, Rubin C-J, Di Palma F, Albert FW, Alfoldi J, Barrio AM, et al. Rabbit genome analysis reveals a polygenic basis for phenotypic change during domestication. Science. 2014;345:1074-9. https://doi.org/10.1126/science.1253714.

56. Nachman MW. Single nucleotide polymorphisms and recombination rate in humans. Trends Genet. 2001;17:481-5. https://doi.org/10.1016/S01689525(01)02409-X.

57. Kong A, Gudbjartsson DF, Sainz J, Jonsdottir GM, Gudjonsson SA, Richardsson $\mathrm{B}$, et al. A high-resolution recombination map of the human genome. Nat Genet. 2002;31:241-7. https://doi.org/10.1038/ng917.

58. Trakooljul N. Molecular and association analyses of the androgen receptor gene as a candidate for production and reproduction traits in pigs: University of Bonn; 2004

59. Payer B, Lee JT. X chromosome dosage compensation: how mammals keep the balance. Annu Rev Genet. 2008:42:733-72.

60. Yang J, Benyamin B, McEvoy BP, Gordon S, Henders AK, Nyholt DR, et al. Common SNPs explain a large proportion of the heritability for human height. Nat Genet. 2010;42:565-9. https://doi.org/10.1038/ng.608.

61. Gudbjartsson DF, Walters GB, Thorleifsson G, Stefansson H, Halldorsson BV, Zusmanovich $P$, et al. Many sequence variants affecting diversity of adult human height. Nat Genet. 2008:40:609-15. https://doi.org/10.1038/ng.122.

62. Visscher PM. Sizing up human height variation. Nat Genet. 2008;40:489-90. https://doi.org/10.1038/ng0508-489.

63. Hirschhorn JN, Lettre G. Progress in genome-wide association studies of human height. Horm Res 2009;71 Suppl 2 Suppl. 2:5-13. https://doi.org/10 $1159 / 000192430$.

64. Signer-Hasler H, Flury C, Haase B, Burger D, Simianer H, Leeb T, et al. A genome-wide association study reveals loci influencing height and other conformation traits in horses. PLoS One. 2012;7:e37282. https://doi.org/10. 1371/journal.pone.0037282.

65. Karim L, Takeda H, Lin L, Druet T, Arias JAC, Baurain D, et al. Variants modulating the expression of a chromosome domain encompassing PLAG1 influence bovine stature. Nat Genet. 2011;43:405-13. https://doi.org/10.1038/ng.814.

66. Johansen T, Hansen HS, Richelsen B, Malmlöf R. The obese Göttingen minipig as a model of the metabolic syndrome: dietary effects on obesity, insulin sensitivity, and growth hormone profile. Comp Med. 2001;51:150-5.

67. Tuomi J. Mammalian reproductive strategies: a generalized relation of litter size to body size. Oecologia. 1980;45:39-44. https://doi.org/10.1007/BF00346705.

68. Ferguson PW, Harvey WR, Irvin KM. Genetic, phenotypic and environmental relationships between sow body weight and sow productivity traits. J Anim Sci. 1984;60:375-84.

69. Li H, Durbin R. Fast and accurate short read alignment with burrowswheeler transform. Bioinformatics. 2009;25:1754-60. https://doi.org/10.1093/ bioinformatics/btp324.

70. Li H, Handsaker B, Wysoker A, Fennell T, Ruan J, Homer N, et al. The sequence alignment/map format and SAMtools. Bioinformatics. 2009;25: 2078-9. https://doi.org/10.1093/bioinformatics/btp352.

71. Picard. 2009. http://broadinstitute.github.io/picard/. Accessed 26 July 2013.

72. DePristo MA, Banks E, Poplin R, Garimella KV, Maguire JR, Hartl C, et al. A framework for variation discovery and genotyping using next-generation DNA sequencing data. Nat Genet. 2011:43:491-8. https:/doi.org/10.1038/ng.806.

73. McKenna A, Hanna M, Banks E, Sivachenko A, Cibulskis K, Kernytsky A, et al. The genome analysis toolkit: a MapReduce framework for analyzing nextgeneration DNA sequencing data. Genome Res. 2010;20:1297-303. https:// doi.org/10.1101/gr.107524.110.

74. R Core Team. R: A language and environment for statistical computing. http://www.r-project.org/. 2015.

75. Nielsen R, Williamson S, Kim Y, Hubisz MJ, Clark AG, Bustamante C. Genomic scans for selective sweeps using SNP data. Genome Res. 2005;15:1566-75.

76. Weir BS, Genetic data analysis II. Methods for discrete population genetic data. Sunderland. Massachusetts: Sinauer Associates; 1996.

77. Danecek P, Auton A, Abecasis G, Albers CA, Banks E, DePristo MA, et al. The variant call format and VCFtools. Bioinformatics. 2011;27:2156-8. https://doi. org/10.1093/bioinformatics/btr330.

78. Purcell S, Neale B, Todd-Brown K, Thomas L, Ferreira MAR, Bender D, et al. PLINK: a tool set for whole-genome association and population-based linkage analyses. Am J Hum Genet. 2007;81:559-75. https:/doi.org/10.1086/519795.

79. Felsenstein J. PHYLIP -- phylogeny inference package (version 3.2). Cladistics. 1989;5:165-6.
80. Cunningham F, Amode MR, Barrell D, Beal K, Billis K, Brent S, et al. Ensembl 2015. Nucleic Acids Res. 2014;43:D662-9. https://doi.org/10.1093/nar/gku1010.

81. Sachs L, Hedderich J. Angewandte Statistik. 12. Berlin Heidelberg New York: Springer-Verlag; 2006.

82. Cramér H. Mathematical methods of statistics. Almqvist \& Wiksells: Uppsala, Sweden; 1945.

83. Gene Ontology Consortium TGO. Gene ontology consortium: going forward. Nucleic Acids Res. 2015;43(Database issue):D1049-56. https://doi. org/10.1093/nar/gku1179.

84. SAS. SAS/STAT(R) 13.1 User's Guide. https://support.sas.com/documentation/ cdl/en/statug/66859/HTML/default/viewer.htm, Accessed 2017-04-26. 2017.

85. Gautier M, Vitalis R. Rehh: an R package to detect footprints of selection in genome-wide SNP data from haplotype structure. Bioinformatics. 2012;28: 1176-7. https://doi.org/10.1093/bioinformatics/bts115.

86. Hu Z-L, Park CA, Wu X-L, Reecy JM. Animal QTLdb: an improved database tool for livestock animal QTL/association data dissemination in the postgenome era. Nucleic Acids Res. 2013;41(Database issue):D871-9. https://doi. org/10.1093/nar/gks1150

87. Zhou S, Lechpammer S, Greenberger JS, Glowacki J. Hypoxia inhibition of Adipocytogenesis in human bone marrow stromal cells requires transforming growth factor-/Smad3 signaling. J Biol Chem. 2005;280: 22688-96. https://doi.org/10.1074/jbc.M412953200.

88. Ma L, Murea M, Snipes JA, Marinelarena A, Krüger J, Hicks PJ, et al. An ACACB variant implicated in diabetic nephropathy associates with body mass index and gene expression in obese subjects. PLoS One. 2013;8: e56193. https://doi.org/10.1371/journal.pone.0056193.

89. Muise ES, Souza S, Chi A, Tan Y, Zhao X, Liu F, et al. Downstream signaling pathways in mouse adipose tissues following acute in vivo administration of fibroblast growth factor 21. PLoS One. 2013;8:e73011. https://doi.org/10. 1371/journal.pone.0073011.

90. Llamazares M, Obaya AJ, Moncada-Pazos A, Heljasvaara R, Espada J, LópezOtín C, et al. The ADAMTS12 metalloproteinase exhibits anti-tumorigenic properties through modulation of the Ras-dependent ERK signalling pathway. J Cell Sci 2007;120 Pt 20:3544-3552. https://doi.org/10.1242/jcs.005751.

91. Wang D, Han S, Peng R, Jiao C, Wang X, Han Z, et al. DUSP28 contributes to human hepatocellular carcinoma via regulation of the p38 MAPK signaling. Int J Oncol. 2014;45:2596-604.

92. Vallet JL, Miles JR, Freking BA. Effect of fetal size on fetal placental hyaluronan and hyaluronoglucosaminidases throughout gestation in the pig. Anim Reprod Sci. 2010;118:297-309. https://doi.org/10.1016/j.anireprosci.2009.06.019.

93. Roignant J-Y, Treisman JE. Exon junction complex subunits are required to splice Drosophila MAP kinase, a large heterochromatic gene. Cell. 2010;143: 238-50. https://doi.org/10.1016/j.cell.2010.09.036.

94. Cobb MH, Boulton TG, Robbins DJ. Extracellular signal-regulated kinases: ERKs in progress. Cell Regul. 1991;2:965-78.

95. Riedl S, Giedion A, Schweitzer K, Müllner-Eidenböck A, Grill F, Frisch H, et al. Pronounced short stature in a girl with tricho-rhino-phalangeal syndrome ॥ (TRPS II, Langer-Giedion syndrome) and growth hormone deficiency. Am J Med Genet A. 2004;131:200-3. https://doi.org/10.1002/ajmg.a.30374.

96. Sanchez-Infantes D, White UA, Elks CM, Morrison RF, Gimble JM, Considine $\mathrm{RV}$, et al. Oncostatin $\mathrm{m}$ is produced in adipose tissue and is regulated in conditions of obesity and type 2 diabetes. J Clin Endocrinol Metab. 2014;99: 217-25. https://doi.org/10.1210/jc.2013-3555.

97. Kazlauskas A. Plakophilin-2 promotes activation of epidermal growth factor receptor. Mol Cell Biol. 2014;34:3778-9. https://doi.org/10.1128/MCB.00968-14.

98. Park JC, Kim SC, Lee SD, Jang HC, Kim NK, Lee SH, Jung HJ, Kim IC, Seong $\mathrm{HH}$, Choi BH. Effects of Dietary Fat Types on Growth Performance, Pork Quality, and Gene Expression in Growing-finishing Pigs. Asian-Australasian J Anim Sci. 2012:25:1759-67.

99. Hendriks WJAJ, Dilaver G, Noordman YE, Kremer B, Fransen JAM. PTPRR protein tyrosine phosphatase isoforms and locomotion of vesicles and mice. Cerebellum. 2009;8:80-8. https://doi.org/10.1007/s12311-008-0088-y.

100. Juarez JC, Manuia M, Burnett ME, Betancourt O, Boivin B, Shaw DE, et al. Superoxide dismutase 1 (SOD1) is essential for H2O2-mediated oxidation and inactivation of phosphatases in growth factor signaling. Proc Natl Acad Sci U S A. 2008;105:7147-52. https://doi.org/10.1073/pnas.0709451105. 